\title{
A Distributed Charge Transfer Model for IT-SOFCs Based on Ceria Electrolytes
}

\author{
Morteza Rahmanipour, ${ }^{a}$ Alfonsina Pappacena, ${ }^{\mathrm{b}}$ Marta Boaro, ${ }^{\mathrm{b}, *}$ and Alessandro Donazzi ${ }^{\mathrm{a}, *, \mathrm{z}}$ \\ ${ }^{a}$ Dipartimento di Energia, Politecnico di Milano, 20156, Milan, Italy \\ ${ }^{b}$ Dipartimento Politecnico di Ingegneria e Architettura, Università degli Studi di Udine, 33100, Udine, Italy
}

\begin{abstract}
A distributed charge transfer model for IT-SOFCs with MIEC electrolyte and composite electrodes is developed. A physically-based description of the electronic leakage current in the electrolyte is included, together with mass and charge conservation equations. The model is applied to simulate experimental polarization curves and impedance spectra collected on IT-SOFCs consisting of SDC electrolytes, Cu-Pd-CZ80 infiltrated anodes and LSCF/GDC composite cathodes. Hydrogen electro-oxidation experiments are examined $\left(\mathrm{H}_{2} / \mathrm{N}_{2}\right.$ humidified mixtures, $700^{\circ} \mathrm{C}, 30-100 \% \mathrm{H}_{2}$ molar fraction). A significant increase of the ohmic resistance measured in the impedance spectra is revealed at decreasing the $\mathrm{H}_{2}$ partial pressure or increasing the voltage (from $0.71 \Omega \mathrm{cm}^{2}$ at $100 \% \mathrm{H}_{2}$ to $0.81 \Omega \mathrm{cm}^{2}$ at $30 \% \mathrm{H}_{2}$ ). Good agreement between the calculated and experimental polarization and EIS curves is achieved by fitting the exchange current density and the capacitance of each electrode. Model and theoretical analyses allow to rationalize the observed shift of the ohmic resistance, highlighting the key-role played by the electronic leakage current. Overall, the model is able to capture significant kinetic features of IT-SOFCs, and allows to gain insight into relevant parameters for the optimal design of the cell (electrochemically active thickness, current and potential distribution, mass diffusion gradients).

(C) The Author(s) 2017. Published by ECS. This is an open access article distributed under the terms of the Creative Commons Attribution 4.0 License (CC BY, http://creativecommons.org/licenses/by/4.0/), which permits unrestricted reuse of the work in any medium, provided the original work is properly cited. [DOI: 10.1149/2.1911712jes] All rights reserved.

(cc) BY
\end{abstract}

Manuscript submitted July 20, 2017; revised manuscript received September 5, 2017. Published September 15, 2017.

Samaria doped Ceria (SDC) and Gadolinia doped Ceria (GDC) are reference electrolyte materials for intermediate temperature solid oxide fuel cell (IT-SOFC) applications, thanks to their high ionic conductivity between $500^{\circ} \mathrm{C}$ and $700^{\circ} \mathrm{C}^{1-5}$ Associated to a high ionic conductivity, however, these materials show mixed ionic and electronic conductive (MIEC) properties, and their electronic conductivity increases when exposed to reducing atmospheres. The MIEC character of the electrolyte, in turn, results in the onset of electronic leakage currents (or short circuit currents) and low open-circuit voltage values. The leakage current has a chemical origin and is due to the partial reduction of $\mathrm{Ce}^{4+}$ ions to $\mathrm{Ce}^{3+}$ ions, prompted by the different chemical potential at the electrodes: this current is active also in the absence of an electric field applied on the cell, since it stems from the spontaneous transfer of ions across the lattice structure. As a consequence, the effects of the leakage current are not confined to the electrolyte, but extend to the electrodes, and entail a complex relationship with the current drawn from the cell. ${ }^{6}$ Deeper insight can therefore be achieved by mathematical modeling.

In the literature, comprehensive models can be found, which take into account the MIEC properties of Ce-based electrolytes. Starting from continuum rigorous descriptions, a series of models has been derived for the prediction of impedance spectra collected on MIEC electrolytes, the most important examples being those by Jamnik and Maier, ${ }^{7}$ by the group of Haile ${ }^{8,9}$ and by Atkinson et al. ${ }^{10}$ These models propose closed-form, equivalent circuit-like equations, which allow to calculate several relevant parameters of mixed conductors by fitting the spectra, such as the activation energy, the conductivity and the mobility of the ionic and electronic transport processes, the enthalpy and the entropy of reduction, the electrolytic domain boundary, the chemical capacitance, as well as the concentration of the electronic carriers. The experimental and model results concurrently show that the electrical conductivity of the electrolyte leads to modifications of the measured ohmic resistance, as well as of the shape of the electrode impedance (from a Warburg-like to a symmetric semi-circular arc).

Other than focusing on the individual properties of the electrolyte alone, the group of Wachsman ${ }^{11,12}$ developed a continuum-level model for cells with MIEC electrolytes. The authors derive analytical equations by coupling the Nernst-Plank relationship for charge transfer in the electrolyte with the Butler-Volmer formalism for activation overpotential losses across the electrolyte/electrode interface. The model

*Electrochemical Society Member.

${ }^{\mathrm{z} E}$-mail: alessandro.donazzi@polimi.it is steady state and the electrodes are treated as zero-dimensional: essential feature is the inclusion of potential-dependent, irreversible electrodes as boundary conditions, accompanied by equations from defect thermochemistry. The model is validated on the basis of experimental polarization curves by fitting three parameters, among the thermodynamic and kinetic ones. A most important result, evidenced by the nature of the model equations and of the tuning parameters, is the dependence of the thermodynamics of the electrolyte from the electrode properties, which allows to show that the electrode properties influence the leakage current and the open circuit voltage. A similar approach is also proposed by Shen et al. ${ }^{13}$ A one dimensional, steady state model of an IT-SOFC with a MIEC electrolyte is developed, and closed-form equations are provided to predict the leakage current and the open cell voltage, which include the effect of activation and concentration overpotentials. Although the approach is interesting, a zero-dimensional cathode is considered and the anode is assumed as perfectly reversible.

Detailed, one-dimensional descriptions of the electrodes under both steady state and dynamic conditions are frequently found for cells with insulating Yttria stabilized Zirconia (YSZ) electrolytes. Several models take into account composite electrodes, wherein the three phase boundary is percolated and extends along the whole electrode volume. ${ }^{14-22}$ With different degrees of complexity, these models describe the key-characteristics of the cell architecture, and reveal the extension of the electrochemical active region inside the electrodes, as well as the distribution of ionic and electronic currents. Zhu and $\mathrm{Kee}^{18}$ developed a detailed charge distributed model to predict the polarization curves measured on traditional LSM-YSZ/YSZ/NiYSZ cells operating under humidified $\mathrm{H}_{2}$ and $\mathrm{CH}_{4} / \mathrm{H}_{2} \mathrm{O}$ mixtures at $800^{\circ} \mathrm{C}$. More recently, Bertei et al..$^{20}$ propose a dynamic, distributed charge-transfer model for an anode supported LSCF/GDC/YSZ/NiYSZ segmented cell, which allows to closely predict and deconvolute experimental impedance spectra collected with $\mathrm{H}_{2} / \mathrm{H}_{2} \mathrm{O}$ mixtures at $750^{\circ} \mathrm{C}$. A continuum level approach is adopted, and the effective parameters are derived based on the numerical reconstruction of the microstructure with packing algorithms. The model also includes a multistep kinetic scheme, and the presence of multiple double-layer charged interfaces. A detailed analysis of the prevailing physical and chemical phenomena is achieved. The cell, however, makes use of a YSZ electrolyte and of a GDC interlayer, and a description of the leakage current is not required.

A general review of the literature seems to indicate that, on the one hand, the available descriptions of MIEC-based cells are steady state, whereas, on the other hand, dynamic, charge-distributed models 
are developed for cells with YSZ electrolytes. In the present work, a dynamic and distributed charge-transfer model is presented and validated for a button IT-SOFC with a MIEC electrolyte and composite electrodes fabricated in a previous study ${ }^{23}$ with the aim of developing anodes that operate directly with biogas or biofuels. In order to consistently investigate the performance of the cell, the model takes into account the description of the leakage current based on physically-sound equations. Impedance spectra and polarization curves collected on an electrolyte-supported $\mathrm{Cu}-\mathrm{Pd}-\mathrm{CZ80/SDC/LSFC-GDC}$ button cell are analyzed, and the effects of the leakage current are investigated. The model allows to rationalize important kinetic features, such as the shift of the ohmic resistance observed experimentally at varying the $\mathrm{H}_{2}$ partial pressure and the voltage applied to the cell.

\section{Experimental}

Samaria doped Ceria $\left(\mathrm{Sm}_{0.2} \mathrm{Ce}_{0.8} \mathrm{O}_{1.9}\right)$ electrolyte-supported button cells (20 mm cell diameter, $1 \mathrm{~cm}^{2}$ electrode area) with infiltrated anodes were prepared. A commercial SDC powder (Fuelcellmaterials.com) was used for the electrolyte and for the anode scaffold. Full details regarding the preparation procedure are found in a previous publication. ${ }^{23}$ The main steps can be summarized as follows: a mixture of SDC powders and starch $(30 \mathrm{wt} \%)$ were die-pressed with pure SDC powders, and the resulting bilayer was calcined in air at $1400^{\circ} \mathrm{C}$ for $3 \mathrm{~h}$. A porous SDC scaffold ( $150 \mu \mathrm{m}$ thick) supported on a dense SDC electrolyte $(380 \mu \mathrm{m})$ was obtained. After the calcination of this bilayer, the cathode was deposited on the opposite side of the electrolyte and calcined at $1200^{\circ} \mathrm{C}$ for $2 \mathrm{~h}$. A mixture of LSCF $\left(\mathrm{La}_{0.6} \mathrm{Sr}_{0.4} \mathrm{Co}_{0.2} \mathrm{Fe}_{0.8} \mathrm{O}_{3-\delta}\right)$ and Gadolinia doped Ceria $\left(\mathrm{Gd}_{0.1} \mathrm{Ce}_{0.8} \mathrm{O}_{1.9}\right.$, GDC) with 50/50 weight ratio was chosen for the cathode in order to obtain a constant response for this electrode. The LSCF-GDC ink was mixed with graphite and isopropanol, and the resulting slurry was brushed on the electrolyte. The final cathode layer was $40 \mu \mathrm{m}$ thick. The anode was prepared via the infiltration technique. ${ }^{24}$ The porous SDC scaffold was impregnated with a nitric solution of $\mathrm{Pd}$ and CZ80 (1 wt\% Pd in a nitric Pd/CZ80 solution, CZ80 being a mixture of Ceria and Zirconia with $80 / 20$ weight ratio) and subsequently calcined at $600^{\circ} \mathrm{C}$. The impregnation and calcination steps were repeated until the amount of CZ80 reached $15 \mathrm{wt} \%$. In order to increase the electronic conductivity of the scaffold, a second infiltration round was performed on the anode with a $\mathrm{Cu}\left(\mathrm{NO}_{3}\right)_{2}$ nitric solution, until an additional loading of $15 \mathrm{wt} \% \mathrm{Cu}$ was reached. The final anode composition was $15 \mathrm{wt} \% \mathrm{Cu}, 0.15 \mathrm{wt} \% \mathrm{Pd}$ and $15 \mathrm{wt} \% \mathrm{CZ80}$, in which Pd-CZ is the electroactive phase. The choice of manufacturing a Nickel-free anode is related to the purpose of obtaining cells able to operate at intermediate temperature with biogas and biofuels. Once the preparation was complete, the cell was calcined at $700^{\circ} \mathrm{C}$ for
Table I. Morphological properties of the cell.

\begin{tabular}{ll} 
Parameters & Value \\
\hline Anode $(\mathrm{Cu}-\mathrm{Pd}$-CZ80) & \\
Thickness & $150 \mu \mathrm{m}$ \\
Porosity & $40 \%$ \\
Tortuosity & 2.5 \\
Diameter & $1 \mathrm{~cm}$ \\
Mean pore diameter & $1.0 \mu \mathrm{m}$ \\
Anode particle diameter & $1.0 \mu \mathrm{m}$ \\
$\mathrm{a}_{\mathrm{v}}$ & $5.4 \times 10^{5} \mathrm{~m}^{2} \mathrm{~m}^{-3}$ \\
Cathode $(L S C F-G D C)$ & \\
Thickness & $40 \mu \mathrm{m}$ \\
Porosity & $30 \%$ \\
Tortuosity & 3.3 \\
Diameter & $1 \mathrm{~cm}$ \\
Mean pore diameter & $0.5 \mu \mathrm{m}$ \\
LSCF particle diameter & $0.4 \mu \mathrm{m}$ \\
GDC particle diameter & $0.4 \mu \mathrm{m}$ \\
$\mathrm{a}_{\mathrm{v}}$ & $2.2 \times 10^{5} \mathrm{~m}^{2} \mathrm{~m}^{-3}$ \\
Electrolyte $(S D C)$ & \\
Thickness & $380 \mu \mathrm{m}$
\end{tabular}

$3 \mathrm{~h}$. Silver meshes and ink were applied on the electrodes for current collection.

The morphologic properties of the cell are reported in Table I. Scanning Electron Microscopy images (Carl Zeiss EVO50VP) allowed to measure the thickness of each layer and to investigate the microstructure of the electrodes (Figure 1). The SEM images were taken post-mortem on a spent cell. Mercury porosimetry (AutoPore IV 9500) allowed to determine the porosity of the electrodes and to evaluate the distribution of the pore size. An unimodal distribution was found for both the anode and the cathode, centered at around 1 $\mu \mathrm{m}$ and $0.5 \mu \mathrm{m}$ respectively. The particle size distribution was determined on the precursor powders with a laser granulometer (Cilas 1180). The analyses were performed on $\sim 20 \mathrm{mg}$ samples suspended in isopropanol, after 3 minutes of ultrasonic stirring to break possible agglomerates. The SDC particles size showed a distribution between 0.3 and $1.2 \mu \mathrm{m}$, which peaked at $1 \mu \mathrm{m}$. The LSCF-GDC mixture showed a homogenous and narrow distribution around $0.4 \mu \mathrm{m}$. The SEM images of the electrodes revealed that the particle size distribution of the precursor powders was reasonably retained after sintering and utilization of the cell. In the case of the anode (Figure 1B), good connection was achieved among the SDC particles, but their original shape and size could still be individuated in the sintered structure. As expected, agglomerates of the infiltrated metals (mainly $\mathrm{Cu},<0.1 \mu \mathrm{m}$
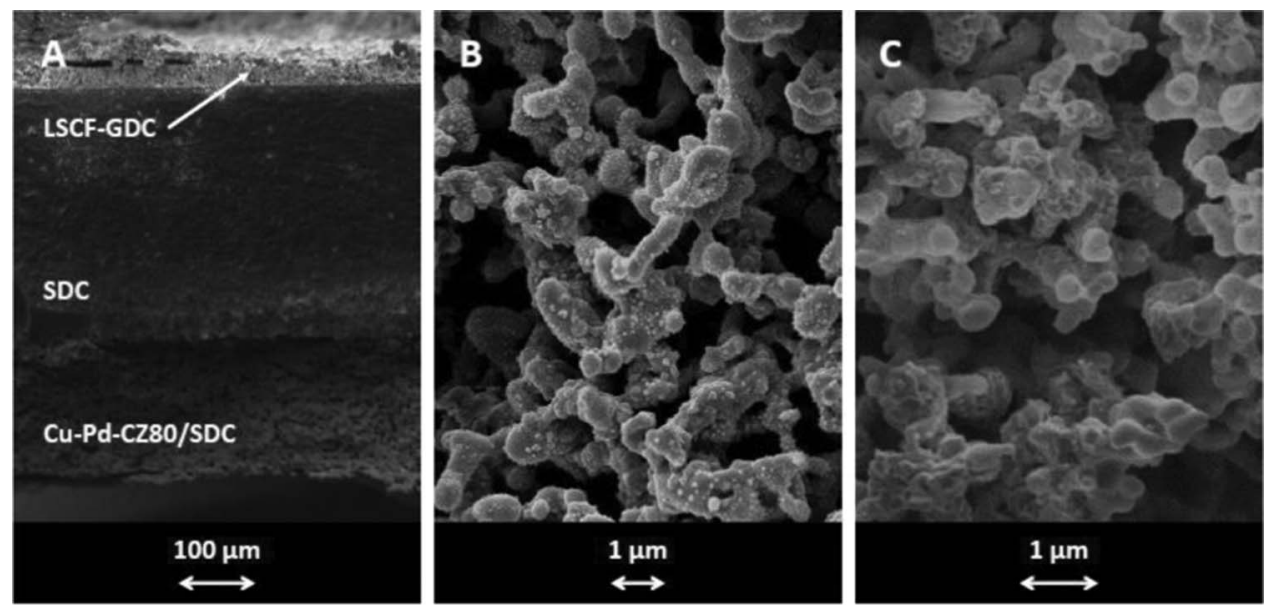

Figure 1. SEM micrographs. A) Cross section of the IT-SOFC. B) Microstructure of the anode. C) Microstructure of the cathode. 
A

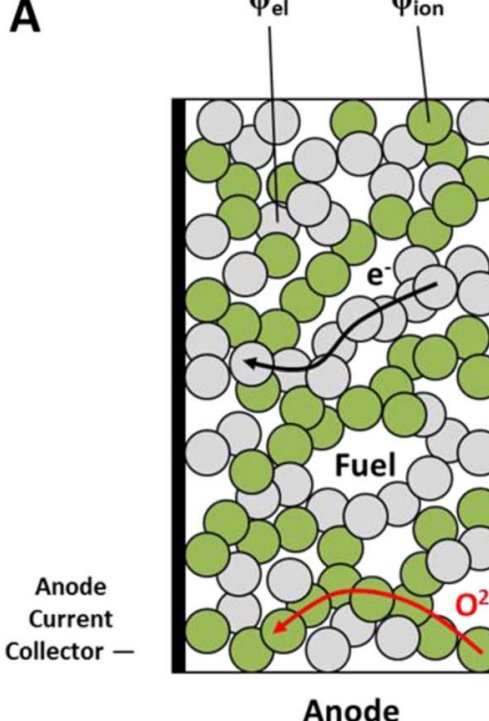

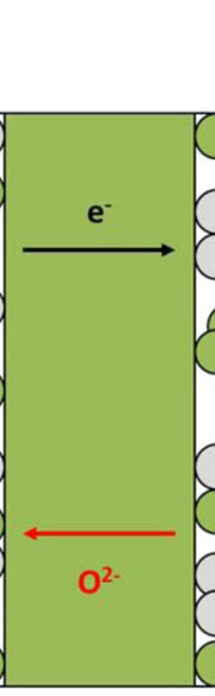

Electrolyte $\varphi_{\text {ion }} \varphi_{\text {el }}$

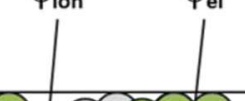
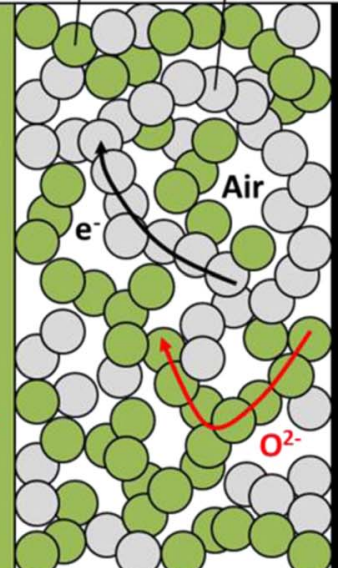

Cathode
B

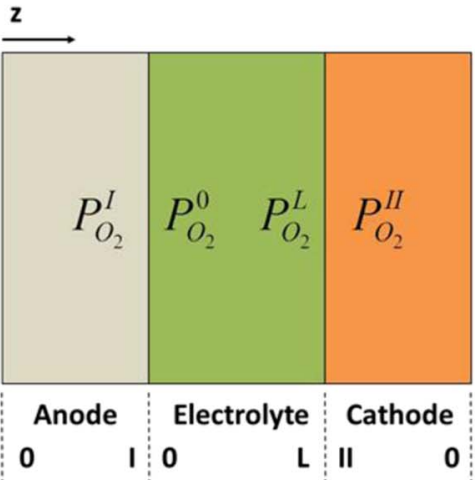

Figure 2. A) Schematic structure of the IT-SOFC. B) Sketch of the model domain.

diameter) were found on the surface of the SDC. An inspection of the cathode (Figure 1C) confirmed that fine particles were present: the individual particles of LSCF and GDC still fell in the initial dimensional range, and gave rise to $\sim 1 \mu \mathrm{m}$ composites after coalescing.

Polarization experiments and electrochemical impedance spectroscopy (EIS) experiments were performed at $700^{\circ} \mathrm{C}$ with $\mathrm{H}_{2} / \mathrm{N}_{2}$ mixtures, varying the $\mathrm{H}_{2}$ molar fraction from $100 \%$ to $30 \%$ (dry basis) and maintaining constant humidification $\left(3 \% \mathrm{H}_{2} \mathrm{O}\right.$ at room temperature). Additional polarization and EIS experiments were carried out at $650^{\circ} \mathrm{C}$ with a humidified $\mathrm{H}_{2}$ mixture $\left(97 \% \mathrm{H}_{2}, 3 \% \mathrm{H}_{2} \mathrm{O}\right)$. An air flow of $100 \mathrm{Ncc} / \mathrm{min}$ was supplied to the cathode, while a flow of $30 \mathrm{Ncc} / \mathrm{min}$ was supplied to the anode. A micro gas chromatograph $(3000 \mathrm{~A}$, Agilent Technologies) allowed to verify the absence of gas leakage between cathode and anode. A potentiostat/galvanostat (Amel 7050) equipped with a frequency response analyzer (520 FRA, Materials Mates) was used for the electrochemical measurements. The polarization experiments were performed by ramping the voltage from the OCV value (Open Cell Voltage) down to $0.4 \mathrm{~V}$ with $50 \mathrm{mV}$ steps. The EIS experiments were performed at OCV and at $0.4 \mathrm{~V}$, in the $10 \mathrm{kHz}$ $-10 \mathrm{mHz}$ frequency range and with $10 \mathrm{mV}$ voltage amplitude.

\section{Model Equations and Variables}

A dynamic, one-dimensional, isothermal, distributed chargetransfer model of an IT-SOFC with a MIEC electrolyte and composite electrodes is presented. Appropriate equations for the leakage current within the electrolyte are included. The model is able to simulate the polarization curves and the impedance spectra of a button cell running on $\mathrm{H}_{2} / \mathrm{H}_{2} \mathrm{O} / \mathrm{N}_{2}$ mixtures. Along each component of the cell, the profiles of concentration, overpotential, electronic and ionic potentials, as well as electronic and ionic currents are described. The basic assumptions are:

- Gases are ideal.

- Radial gradients are neglected.

- The materials are isotropic and homogeneous (continuum-level approach).

- The electronic leakage current in the electrolyte is constant.

- The current collectors are zero-dimensional.

- The infiltrated anode can be modeled as a composite electrode.

The absence of radial gradients is reasonable, since the diameter of the cell is small enough and the fluxes of the feed gases are high and orthogonally oriented toward the electrodes surfaces. A small recirculation volume is left between the gas supply hose and the electrode surface. The assumption of isotropic materials implies that issues such as discontinuities and micro-cracks are minimized during the cell preparation. The non-dimensionality of the current collectors implies that the contact resistance with the electrodes is considered negligible. The last assumption regarding the adequacy of the modeling approach means that the description adopted for the infiltrated anode is based on the same conservation equations and overpotential definition typically used for composite architectures. Figure $2 \mathrm{~A}$ shows a representation of the cell structure, while Figure 2B shows the computational domain. The governing equations are discussed first, then the required set of boundary conditions are specified, and finally the numerical procedure for solving the system is outlined.

Governing equations.-The cell potential is a function of the gas composition in the electrodes. For each species, the problem of diffusion in a porous media is described by coupling the mass conservation equations with the dusty gas model (DGM) equations.

$$
\varepsilon \cdot \frac{d C_{i}}{d t}=-\frac{d J_{i}}{d z}+a_{V} \cdot \sum_{j=1}^{N R} \nu_{i, j}^{\text {electro }} \cdot r_{j}^{\text {electro }}
$$

$$
\frac{d C_{i}}{d z}+\sum_{j=1}^{N S} \frac{C_{j} \cdot J_{i}-C_{i} \cdot J_{j}}{C_{t o t} \cdot D_{i, j}^{m o l, e f f}}+\frac{J_{i}}{D_{i}^{k n u, e f f}}+\frac{B}{\mu} \cdot \frac{C_{i}}{D_{i}^{k n u, e f f}} \cdot \frac{d P}{d z}=0
$$

Equation 1 takes into account the influence of the electrochemical reactions $\left(r^{\text {electro }}\right)$ ) on the gradient of diffusive molar flow. It is important to note that the active surface for the electrochemical processes $\mathrm{a}_{\mathrm{V}}$ at the anode and at the cathode is intended in two different ways. The electrochemically active surface area of the anode is estimated starting from that a packed bed of spheres multiplied by an appropriate coefficient, which takes into account the partial coverage by the electrocatalyst (Eq. 3). In fact, given that the anode was prepared by infiltration of the SDC scaffold with the $\mathrm{Cu} / \mathrm{Pd} / \mathrm{CZ} 80$ mixture, it is assumed that the anodic electrochemically active surface is exclusively defined by the contact area between the SDC scaffold and the infiltrated CZ80 phase, which is present with a weight fraction $f$ equal to 0.15 . On the one hand, this assumption implies that the CZ80 formed a homogenous film on the SDC surface, with no agglomeration or multiple layers. On the other hand, the assumption implies that $\mathrm{Cu}$ is electrochemically inert, and that the limited amount of Pd does not 
provide a significant contact surface.

$$
a_{V}=\frac{6 \cdot(1-\varepsilon)}{d_{p}} \cdot f
$$

Considering that the cathode is a composite, the interfacial contact area between LSCF and GDC particles is taken as active. This area is estimated according to the procedure detailed by Chen et al., ${ }^{25}$ based on the measured morphological parameters (Table I) and by setting a contact angle between the particles equal to $15^{\circ}$. Even if the particle size is finer than that of the anode $(0.4 \mu \mathrm{m}$ vs. $1 \mu \mathrm{m})$, a smaller area $\left(2.2 \times 10^{5} \mathrm{~m}^{2} / \mathrm{m}^{3}\right.$ vs. $\left.5.4 \times 10^{5} \mathrm{~m}^{2} / \mathrm{m}^{3}\right)$ is calculated, in line with the experimental evidence that infiltrated electrodes expose a higher active surface than composites.

Equation 2 expresses the variation of the i-species concentration as a function of the diffusive molar flows of all the species in the porous volume. The model accounts for both the molecular diffusion mechanism (Eq. 4) and the Knudsen diffusion mechanism (Eq. 5). The electrodes tortuosity is simply evaluated as the inverse of the porosity $(\tau=1 / \varepsilon)$. The presence of the Knudsen diffusion term imposes the introduction of the viscous term $(\mu)$, as a function of the pressure variation along the axial coordinate of the electrode. The anodic and cathodic concentrations are defined using the ideal gas law.

$$
\begin{gathered}
D_{M o l, i j}^{e f f}=\frac{0.00143 \cdot T^{1.75}}{P \cdot\left(v_{i}^{1 / 3}+v_{j}^{1 / 3}\right)^{2} \cdot \sqrt{2}} \cdot \sqrt{M M_{i}^{-1}+M M_{j}^{-1}} \\
D_{K n u, i}^{e f f}=\frac{\varepsilon}{\tau} \cdot 0.97 \cdot r_{P} \cdot \sqrt{\frac{T}{M M_{i}}}
\end{gathered}
$$

In order to describe how the ionic and electronic current densities vary along the axis of the cell, charge conservation equations and overpotentials must be considered. In general, the overpotential is defined as the departure of the electrode potential from its equilibrium value. Inside a composite electrode structure, two kinds of potentials are defined, the ionic potential $\varphi_{\text {ion }}$ (associated to the electrolyte iontransferring phase) and the electronic potential $\varphi_{\mathrm{el}}$ (associated to the electron conducting phase). Figure $2 \mathrm{~A}$ shows the structure of the cell, drawing attention to the simultaneous flow of oxide ions and electrons in the electrodes and in the electrolyte. This flow requires the existence of the ionic and electronic potentials. The reaction interface, the current and the potential profiles extend along the entire length of the electrodes. Hence, the activation overpotentials $\eta_{\text {act }}$ (Eq. 6) are a function of the local position in the electrodes.

$$
\eta_{a c t}=\varphi_{e l}-\varphi_{i o n}-E_{r e f}
$$

In the equation, $\mathrm{E}_{\mathrm{ref}}$ is the relative potential difference between the electronic and ionic conductors at reference state. The reference state for the anode activation overpotential is set to zero. Consequently the reference state for the cathode overpotential becomes the reversible Nernst potential. ${ }^{17}$ Equation 6 can be rewritten for the anode and cathode as:

$$
\begin{gathered}
\eta_{a c t}=\varphi_{e l}^{a n}-\varphi_{i o n}^{a n} \\
\eta_{a c t}=\varphi_{e l}^{c a t}-\varphi_{i o n}^{c a t}-E_{r e v}
\end{gathered}
$$

Considering the reaction of $\mathrm{H}_{2}$ oxidation, the Nernst potential is expressed as a function of the species activities (partial pressures under ideal gas assumption) at the local axial position $\mathrm{z}$ as in Equation 9. In this way, the effect of the concentration overpotential is implicitly included.

$$
E_{\text {rev }}=E_{0}-\frac{R \cdot T}{n_{e l} \cdot F} \cdot \ln \frac{P_{H_{2} O}^{a n}\left(z_{a n}\right)}{P_{H_{2}}^{a n}\left(z_{a n}\right) \cdot P_{O_{2}}^{a n}\left(z_{c a t}\right)}
$$

The charge conservation equations within the electrode relate the axial gradient of current (ionic and electronic) with the faradaic current exchanged in the electrochemical semi-reaction. The local charge
Table II. Intrinsic ionic and electronic conductivities.

\begin{tabular}{llc} 
Parameter & Value $\left[\mathrm{S} \mathrm{cm}^{-1}\right]$ & Reference \\
\hline $\begin{array}{l}\text { SDC ionic } \\
\text { conductivity }\end{array}$ & $9.85 \times 10^{4} / \mathrm{T} \exp \left(-65.2 \times 10^{3} / \mathrm{R} / \mathrm{T}\right)$ & 23 \\
$\begin{array}{l}\text { SDC electronic } \\
\text { conductivity }\end{array}$ & $2.5 \times 10^{8} / \mathrm{T} \exp \left(-220 \times 10^{3} / \mathrm{R} / \mathrm{T}\right)^{*} \mathrm{P}_{\mathrm{O} 2}-0.25$ & 23 \\
$\begin{array}{l}\text { GDC ionic } \\
\text { conductivity }\end{array}$ & $1.09 \times 10^{5} / \mathrm{T} \exp \left(-61.7 \times 10^{3} / \mathrm{R} / \mathrm{T}\right)$ & 1 \\
$\begin{array}{l}\text { LSCF electronic } \\
\text { conductivity }\end{array}$ & $-0.627 * \mathrm{~T}+983.25$ with $\mathrm{T}>923 \mathrm{~K}$ & 29
\end{tabular}

transfer rates for the oxidation reaction at the anode and for the oxygen reduction at the cathode can be represented in the Butler-Volmer form. Assuming that the local reversible potential $\mathrm{E}_{\mathrm{rev}}$ is constant with time, the charge conservation equations are written as follows:

$$
\begin{aligned}
a_{V} \cdot \hat{C} \cdot \frac{d \eta_{a c t}}{d t}=-\frac{d i_{e l}}{d z}-a_{V} \cdot i_{0} \\
\quad \cdot\left[\exp \left(\frac{\alpha \cdot n_{e^{-}} \cdot F \cdot \eta_{a c t}}{R \cdot T}\right)-\exp \left(\frac{-(1-\alpha) \cdot n_{e^{-}} \cdot F \cdot \eta_{a c t}}{R \cdot T}\right)\right]
\end{aligned}
$$

$$
\begin{aligned}
& -a_{V} \cdot \hat{C} \cdot \frac{d \eta_{a c t}}{d t}=-\frac{d i_{i o n}}{d z}+a_{V} \cdot i_{0} \\
& \quad\left[\exp \left(\frac{\alpha \cdot n_{e^{-}} \cdot F \cdot \eta_{a c t}}{R \cdot T}\right)-\exp \left(\frac{-(1-\alpha) \cdot n_{e^{-}} \cdot F \cdot \eta_{a c t}}{R \cdot T}\right)\right]
\end{aligned}
$$

$\alpha$ is the symmetry factor and $i_{0}$ is the exchange current density, which is defined based on the kinetic mechanism of electro-oxidation. Two equations are written for each electrode. The values of the double layer capacitances are unknown parameters and are calculated by fitting of the experimental EIS spectra (Numerical procedure). The Ohm's law (Eq. 12) allows to write six differential first-order equations to describe the ionic and the electronic currents and potentials in the electrodes and in the electrolyte.

$$
i+\sigma \cdot \frac{d \varphi}{d z}=0
$$

Effective ionic and electronic conductivities appear in the Ohm's law of the electrodes. These values are calculated by reducing the intrinsic conductivity of the materials with an effectiveness factor, estimated based on the volume fraction of the conductive phase $\psi \cdot{ }^{17}$

$$
\sigma^{e f f}=\sigma \cdot \psi^{3 / 2}
$$

The intrinsic ionic and electronic conductivities are reported in Table II. The ionic conductivity of SDC is derived from experiments on sintered pellets and is coherent with the values reported by Gödickemeier et al. ${ }^{26}\left(0.65 \mathrm{eV}, \sigma_{\text {ion }}=3.47 \times 10^{-2} \mathrm{~S} / \mathrm{cm}\right.$ at $\left.700^{\circ} \mathrm{C}\right)$ and by Zhang et al. ${ }^{27}\left(0.64 \mathrm{eV}, 2.1 \times 10^{-2} \mathrm{~S} / \mathrm{cm}\right)$. The electronic conductivity of SDC is taken from a previous modeling work by our group, ${ }^{23}$ which is also in line with relevant literature. ${ }^{9,13,28}$ In the case of the anode, the scaffold is infiltrated with $\mathrm{Cu}$, whose role is to enhance the electrical conductivity (at $700^{\circ} \mathrm{C}, 6 \times 10^{6} \mathrm{~S} / \mathrm{cm}$ for $\mathrm{Cu}$, $3.8 \times 10^{-1} \mathrm{~S} / \mathrm{cm}$ for SDC with $\left.\mathrm{P} \mathrm{O}_{2}=1.1 \times 10^{-24} \mathrm{~atm}\right)$. A reasonable choice is made by assuming that the electrical conductivity of the SDC backbone increases thanks to the presence of $\mathrm{Cu}$. A value of $4 \mathrm{~S} / \mathrm{cm}$ is then adopted for the intrinsic electrical conductivity of the anode. In the case of the cathode, even though LSCF is a MIEC material, a reasonable choice is made by assuming that LSCF acts exclusively as the electronic conductive phase and GDC behaves as the ionic conductive phase. As a matter of fact, the ionic conductivity of GDC is higher to that of LSCF at $700^{\circ} \mathrm{C}\left(5.4 \times 10^{-2} \mathrm{~S} / \mathrm{cm}\right.$ vs. 3.6 $\times 10^{-3} \mathrm{~S} / \mathrm{cm}$ ), while the electronic conductivity in air is significantly 
smaller $\left(6 \times 10^{-7} \mathrm{~S} / \mathrm{cm}\right.$ atm vs. $4 \times 10^{2} \mathrm{~S} / \mathrm{cm}$ at $\left.700^{\circ} \mathrm{C}\right)$. In Table II, a simple linear relationship is provided, which we adapted from the data provided for $\mathrm{La}_{0.6} \mathrm{Sr}_{0.4} \mathrm{Co}_{0.2} \mathrm{Fe}_{0.8} \mathrm{O}_{3-\delta}$ by Stevenson et al. ${ }^{29}$ It is indeed well-known that the electronic conductivity of LSCF shows a maximum as a function of the temperature, which is due to the transition from the electronic to the ionic compensation behavior. In the range between $650^{\circ} \mathrm{C}$ to $800^{\circ} \mathrm{C}$, the ionic compensation prevails with an almost linear decay of the conductivity with temperature. ${ }^{30}$

In a MIEC electrolyte, the charge transfer by the oxide ions is accompanied by a contribution from the electrons. Together with the ionic current and potential, additional variables must be introduced to describe this feature. The leakage current $\left(\mathrm{i}^{\mathrm{ely}} \mathrm{el}\right)$ is indeed a function of the oxygen partial pressure at the interfaces between the electrolyte and the electrodes, as well as of the chemical potential of the oxide ions in the electrolyte itself. Equivalent oxygen partial pressure is a way to represent the chemical potential of the oxide ions inside the MIEC electrolyte. ${ }^{3,13,31}$ According to the usual phenomenological correlation, the electronic conductivity depends on the equivalent oxygen partial pressure, while the ionic conductivity does not. Considering the Ohm's law, the electronic leakage current in the electrolyte is expressed as:

$$
i_{e l}^{e l y}+\sigma_{e l}^{0} \cdot P_{O_{2}}^{-1 / 4} \cdot \frac{d \varphi_{e l}^{e l y}}{d z}=0
$$

According to the model assumptions, the leakage current is constant, meaning that the electrical potential in the electrolyte varies axially. Once the relationship between the electrical variables is established, the equivalent oxygen partial pressure must be defined along the electrolyte axis. To do so, the scheme proposed by Shen et al. ${ }^{13}$ is adopted. Advantages of this scheme are its simplicity and physicallysound bases, being derived from the Nernst-Plank equation. The reference configuration for the leakage current in the model domain is reported in Figure 2B: the current direction from anode to cathode is taken as positive, thus the ionic current is positive and the electronic current is negative. This opposite direction is due to the different driving forces of ions and electrons. The electronic current density in the electrolyte is calculated as:

$$
i_{\text {el }}^{\text {ely }}=\frac{i_{\text {ion }}^{\text {ely }}}{\sigma_{\text {ion }}^{\text {ely }}} \cdot \frac{\sigma_{e l}^{0}}{M_{0}-1} \cdot\left[M_{0} \cdot\left(P_{O_{2}}^{0}\right)^{-1 / 4}-\left(P_{O_{2}}^{L}\right)^{-1 / 4}\right]
$$

where:

$$
M_{0}=\exp \left(-\frac{F}{R \cdot T} \cdot \frac{i_{\text {ion }}^{\text {ely }}}{\sigma_{\text {ion }}^{\text {ely }}} \cdot L\right)
$$

To compute the ionic current density in the electrolyte, the charge neutrality requirement must be satisfied.

$$
i_{\text {el }}^{e l y}+i_{\text {ion }}^{e l y}-i_{\text {cell }}=0
$$

Once the values of the ionic and the electronic current densities in the electrolyte are derived, the profile of equivalent oxygen partial pressure in the electrolyte is calculated:

$$
\begin{gathered}
{\left[P_{O_{2}}(z)\right]^{-1 / 4}=\left[\left(P_{O_{2}}^{0}\right)^{-1 / 4}-\frac{i_{\text {el }}^{e l y} \cdot \sigma_{i o n}}{i_{\text {ion }}^{\text {ely }} \cdot \sigma_{\text {el }}^{0}}\right]} \\
\cdot \exp \left(-\frac{F}{R \cdot T} \cdot \frac{i_{\text {ion }}^{\text {ety }}}{\sigma_{i o n}} \cdot z\right)+\frac{i_{\text {el }}^{\text {ely }} \cdot \sigma_{i o n}}{i_{\text {ion }}^{\text {ely }} \cdot \sigma_{\text {el }}^{0}}
\end{gathered}
$$

The definition of the cell potential completes the sets of equations. The cell potential is the difference between the electronic potentials calculated at the gas/electrode interface $(\mathrm{z}=0$ in Figure $2 \mathrm{~B})$.

$$
E_{\text {cell }}=\left.\varphi_{e l}^{\text {cat }}\right|_{z=0}-\left.\varphi_{e l}^{a n}\right|_{z=0}
$$

Boundary conditions. - With respect to the boundary conditions of the mass balance problem, simple continuously stirred tank reactor (CSTR) equations are adopted at the gas/electrode interface, expressed by the continuity of the incoming and outcoming molar flows. This condition is coherent with the first assumption of the model. A volume of $1.6 \mathrm{~cm}^{3}$ is estimated, being the gas supply hose located $2 \mathrm{~cm}$ off the electrode surface.

$$
V_{C S T R} \cdot \frac{d C_{i}}{d t}=F_{i}^{i n}-F_{i}^{o u t}-J_{i} \cdot A_{\text {cell }}
$$

At the current collector, which is a silver mesh allowing only for electron transport, the ionic current density is null, and the electronic current density is equal to the applied load current. The electronic potential is set at zero at the cathode, and equal to the cell potential at the anode. The derivatives of the ionic potentials are taken as null, consistently with the Ohm's law.

At the electrode/electrolyte interface, the molar flow of the gaseous species is null. Most importantly, given that the electrolyte is a MIEC, the electronic current is not null (as it would be in the case of an insulating electrolyte like YSZ), but is equal to the leakage current (Eq. 15). The condition for the ionic current density stems directly from the conservation equation (Eq. 16). The formulation of the leakage current requires the values of the oxygen partial pressure at the electrode/electrolyte interface to be known. The following boundary conditions are established as a result of an energy conservation analysis:

$$
\begin{aligned}
& \frac{R \cdot T}{4 \cdot F} \cdot \ln \left(\frac{P_{O_{2}}^{\mathrm{II}}}{P_{O_{2}}^{L}}\right)=\left.\eta_{\text {act }}^{\text {cat }}\right|_{\text {cat } / \text { ely }} \\
& \frac{R \cdot T}{4 \cdot F} \cdot \ln \left(\frac{P_{O_{2}}^{0}}{P_{O_{2}}^{\mathrm{I}}}\right)=\left.\eta_{\text {act }}^{\text {an }}\right|_{\text {an } / \text { ely }}
\end{aligned}
$$

$\mathrm{P}^{\mathrm{II}} \mathrm{O}_{2}$ is the oxygen partial pressure at the cathode/electrolyte interface, while $\mathrm{P}_{\mathrm{O}_{2}}^{\mathrm{I}}$ is the equivalent oxygen at the anode/electrolyte interface (Figure $2 \mathrm{~B}$ ). The first value refers to the oxygen pressure directly calculated at cathode/electrolyte interface, while the second value is calculated from the local equilibrium between reactants and products at the anode side (e.g. $\mathrm{H}_{2}$ and $\mathrm{H}_{2} \mathrm{O}$ in the case of the electrooxidation of $\mathrm{H}_{2}$ ). Finally, in the case of the electrolyte, continuity conditions are assigned for ionic and electronic potentials.

Kinetic rates.-The electrochemical reactions of $\mathrm{H}_{2}$ oxidation and $\mathrm{O}_{2}$ reduction are simulated according to global power law rates and to the Butler-Volmer framework. For both the reactions, the symmetry factors $\alpha$, the activation energy and the species orders are taken from our previous work, ${ }^{23}$ dedicated to IT-SOFCs with similar anode and cathode compositions. The values of the exchange current density are unknown parameters and are fitted to describe the polarization curves and the EIS spectra. The kinetic parameters are reported in Table III. An activation energy of $73 \mathrm{~kJ} \mathrm{~mol}^{-1}$ and a dependency of 0.47 were found on $\mathrm{Cu}-\mathrm{Pd}-\mathrm{CZ} 80$ anodes for the rate of $\mathrm{H}_{2}$ electrooxidation, which are retained in the present case. Though, given that that the previous kinetic analysis was carried out on an anode with

Table III. Kinetic parameters at $700^{\circ} \mathrm{C}$.

\begin{tabular}{ll}
$\mathrm{H}_{2}$ electro-oxidation & \\
\hline $\mathrm{i}^{\mathrm{ox}}{ }_{\mathrm{H} 2}$ & $23.8 \mathrm{~A} \mathrm{~m}^{-2} \mathrm{~atm}^{-0.47} \mathrm{~K}^{-1}$ \\
$\mathrm{E}^{\mathrm{ox}}{ }_{\text {act }}$ & $73 \mathrm{~kJ} \mathrm{~mol}^{-1}$ \\
$\alpha_{\mathrm{an}}$ & 0.5 \\
$\alpha_{\mathrm{cat}}$ & 0.5 \\
$\mathrm{C}_{\mathrm{DL}}$ & $95 \mathrm{~F} \mathrm{~m}^{-2}$ \\
$\mathrm{O}_{2}$ electro-reduction & \\
\hline $\mathrm{i}^{\mathrm{re}} \mathrm{O}$ & $2.8 \times 10^{7} \mathrm{~A} \mathrm{~m}^{-2} \mathrm{~atm}^{-0.33} \mathrm{~K}^{-1}$ \\
$\mathrm{E}^{\mathrm{re}}{ }_{\text {act }}$ & $139 \mathrm{~kJ} \mathrm{~mol}^{-1}$ \\
$\alpha_{\mathrm{an}}$ & 0.65 \\
$\alpha_{\mathrm{cat}}$ & 0.35 \\
$\mathrm{C}_{\mathrm{DL}}$ & $1.5 \times 10^{2} \mathrm{~F} \mathrm{~m}^{-2}$ \\
&
\end{tabular}


different morphology and by means of a model which was not chargedistributed, re-estimation of the exchange current density is required.

$$
i_{0}^{a n}=i_{H_{2}}^{o x} \cdot T \cdot \exp \left(-\frac{E_{a c t}^{r e}}{R \cdot T}\right) \cdot P_{H_{2}}^{0.47}
$$

The same approach is followed for the electrochemical reduction of $\mathrm{O}_{2}$. In this case, it is assumed that a reaction order of 0.33 and an activation energy of $139 \mathrm{~kJ} \mathrm{~mol}^{-1}$, which were estimated for pure LSCF cathodes, can fairly be assumed also on the LSCF-GDC composite, while the exchange current density has to be re-estimated.

$$
i_{0}^{c a t}=i_{O_{2}}^{r e} \cdot T \cdot \exp \left(-\frac{E_{a c t}^{o x}}{R \cdot T}\right) \cdot P_{O_{2}}^{0.33}
$$

Numerical procedure.-The model requires solving a differential and algebraic equations (DAE) system. The method of lines is chosen. The length of each cell component is split into an appropriate number of grid points: in each of these points, the spatial derivatives are calculated with the Euler backward differentiation method. In this way, an algebraic nonlinear system is obtained in the axial coordinate, while the time derivatives are retained. The ode $15 \mathrm{~s}$ routine is applied to solve this DAE system. The convergence of the solution is verified by varying the number of grid points ( 100 points spacing were always sufficient). The implicit form of the DGM equations (Eq. 2) leads to an ill-conditioned system, and an appropriate rearrangement is required to achieve the correct numerical solution. The details on the method are found in reference literature works. ${ }^{15,32}$ The calculation of the impedance is performed following the procedure proposed by Bessler: $:^{33}$ the system is first solved at steady state, then the harmonic oscillation is considered. The solutions of the steady state problem constitute the initial conditions of the dynamic impedance problem. Hence, this procedure allows to simultaneously compute one point of the polarization curve and the corresponding EIS spectrum. In the steady state problem, gradient-less initial conditions are assigned in the axial domain, such that the algebraic part of the DAE system is identically solved. In the electrodes, consistent initial conditions require that the gas concentration is equal to the inlet feed concentration, and that the overpotentials and the current densities are zero. In the electrolyte, at time zero, the current densities are calculated with a routine for nonlinear functions. A look at Equation 15 reveals that an infinite value of the leakage current is obtained as the load current tends to zero. For this reason, a small non-zero average current $\left(1 \mu \mathrm{A} / \mathrm{cm}^{2}\right)$ is used for the initial conditions and also for the simulations at OCV. The steady state solution is obtained by ramping the current from initial zero to the desired set point, and maintaining it for a sufficiently long amount of time. In the dynamic problem, the sinusoidal current (Eq. 23) is switched on by setting the average current value equal to the steady state input (is), and assigning the perturbation amplitude $i_{P}$ and the frequency $\omega$. The perturbation amplitude is equal to ten thousand of the steady state, guaranteeing the linear response of the system. In the time domain, the dynamic system is integrated over 20 periods. The full explanation of the impedance calculation is reported elsewhere. ${ }^{18,34}$

$$
i_{\text {cell }}=i_{S}+i_{P} \cdot \sin (\omega \cdot t)
$$

The exchange current densities and the capacitances are unknown parameters, which are calculated by fitting the polarization curves and the impedance spectra to the corresponding experimental data sets. The exchange current densities are calculated by fitting the polarization curves, the capacitances by fitting the impedance spectra. In the first case, a minimization of the residual squared errors is entailed, fixing the current values and minimizing the output voltage (Eq. 26). In the second case, the capacitance values are estimated by minimizing the residual squared error on the imaginary part of the spectra in the Bode plots (imaginary part vs. frequency), following Yang et al. ${ }^{21}$ After the minimization, the adequacy of the parameters is verified based on the best match in the Nyquist plots. A $\chi^{2}$ test is performed on both the imaginary and real part of the spectra (Eq. 27).
In this test, the number of EIS experiments $\left(\mathrm{N}_{\exp }\right)$ is equal to 4 , the number of impedance responses $\left(\mathrm{N}_{\text {resp }}\right)$ is 60 for each EIS experiment; the experimental variance $s^{2}$ exp, is assumed constant and equal to $5 \times$ $10^{-2}$. S exhibited a $\chi^{2}$ distribution with a number of degrees of free$\operatorname{dom} \zeta$ of 236 ( $\zeta=\mathrm{N}_{\text {resp }}-4$ parameters). Multiplicity of the solutions is possible when fitting exclusively to the polarization curves, given that different sets of kinetic parameters can equally well match the data; though, only the set proposed in Table III allows to best describe also the EIS spectra, qualitatively, quantitatively, and maintaining the physical consistency of the parameters.

$$
\begin{gathered}
R S S=\sum_{j=1}^{N_{\text {exp }}}\left(V_{j}^{\exp }-V_{j}^{\text {calc }}\right)^{2} \\
S=\sum_{j=1}^{N_{\text {exp }}} \frac{1}{s_{\text {exp }, j}^{2}} \sum_{i=1}^{N_{\text {resp }}}\left(Z_{i, j}^{\text {exp }}-Z_{i, j}^{\text {calc }}\right)^{2}
\end{gathered}
$$

\section{Results}

The bulk part of the polarization and EIS experiments was performed at $700^{\circ} \mathrm{C}$, varying the molar fraction of $\mathrm{H}_{2}$ from $30 \%$ to $100 \%$ with $\mathrm{N}_{2}$ to balance and constant room temperature humidification. This data set was used for tuning the values of the anodic and cathodic exchange current densities and capacitances. The additional experiment collected at $650^{\circ} \mathrm{C}$ were used to validate the model parameters on a predictive basis (no parameter tuning). The originality of the present results stems from the introduction of a scheme for the leakage current in the distributed charge transfer model, and refers specifically to the simulations of EIS spectra in the presence of the leakage current.

Polarization and EIS experiments.-Experiments at $700^{\circ} \mathrm{C}$.- The polarization curves are reported in Figure 3A. The results are in line with the expected trends: the current density increases with increasing $\mathrm{H}_{2}$ amount, passing from $170 \mathrm{~mA} \mathrm{~cm}^{-2}$ at $30 \% \mathrm{H}_{2}$ to $270 \mathrm{~mA} \mathrm{~cm}$ at $100 \% \mathrm{H}_{2}$ at $0.5 \mathrm{~V}$ load. At no load condition, the OCV values are lower than the corresponding Nernstian ones $(1-1.1 \mathrm{~V})$ due to the presence of the electronic leakage current in the SDC electrolyte. A reduction of the OCV from $0.87 \mathrm{~V}$ at $100 \% \mathrm{H}_{2}$ to $0.86 \mathrm{~V}$ at $30 \% \mathrm{H}_{2}$ is also noted. These results are consistent with other literature reports dedicated to cells based on SDC electrolytes with similar thickness (Table IV): $\mathrm{Lu}$ et $\mathrm{al}^{35,36}$ find an OCV of $0.85 \mathrm{~V}$ when operating an infiltrated $\mathrm{Cu}-\mathrm{CeO}_{2}-\mathrm{SDC} / \mathrm{SDC} / \mathrm{LSCF}$ cell with humidified $\mathrm{H}_{2}$ at $700{ }^{\circ} \mathrm{C}$; Matsui et al. ${ }^{37}$ measure $\mathrm{OCV}$ values between 0.85 and $0.90 \mathrm{~V}$ with different cells based on the same SDC electrolyte; Fang et al. ${ }^{38}$ report an OCV of $0.81 \mathrm{~V}$ for $\mathrm{Ni}-\mathrm{SDC} / \mathrm{SDC} / \mathrm{Sr}$-cobaltite cells with 500 $\mu \mathrm{m}$ electrolyte thickness. It is also worthy to compare these OCV values with some exemplary literature values taken from cells with GDC electrolytes tested at $700^{\circ} \mathrm{C} .{ }^{39-42}$ Although caution must be taken since the OCV depends on the electrode polarization (and therefore a fair comparison should be done with strictly identical electrodes), GDC and SDC achieve similar voltages when the electrolyte thickness is almost the same. As the electrolyte becomes thinner, a decrease of the OCV occurs due to the growth of the leakage current density. ${ }^{11,12}$

The impedance curves are reported in Figure 3B. Two main features are readily apparent: on the one hand, the curves are not round shaped, but locally depressed; on the other hand, the ohmic resistance progressively increases when the amount of $\mathrm{H}_{2}$ in the feed decreases. The first feature is common in impedance analyses, and it is due to the overlapping of electrochemical and physic phenomena, as well as to the non-ideal morphology of the microstructure. In general, at least four contributions are present in the spectrum of a cell, namely the contribution of the anodic polarization resistance, the contribution of the cathodic polarization resistance, and the diffusive contribution of each electrode. The non-ideal morphology of the electrodes in terms of particle size distribution, porosity and active surface causes a deformation of the arcs and a distribution of the characteristic times. A 
Pd-Cu-CZ80/SDC/LSCF-GDC cell
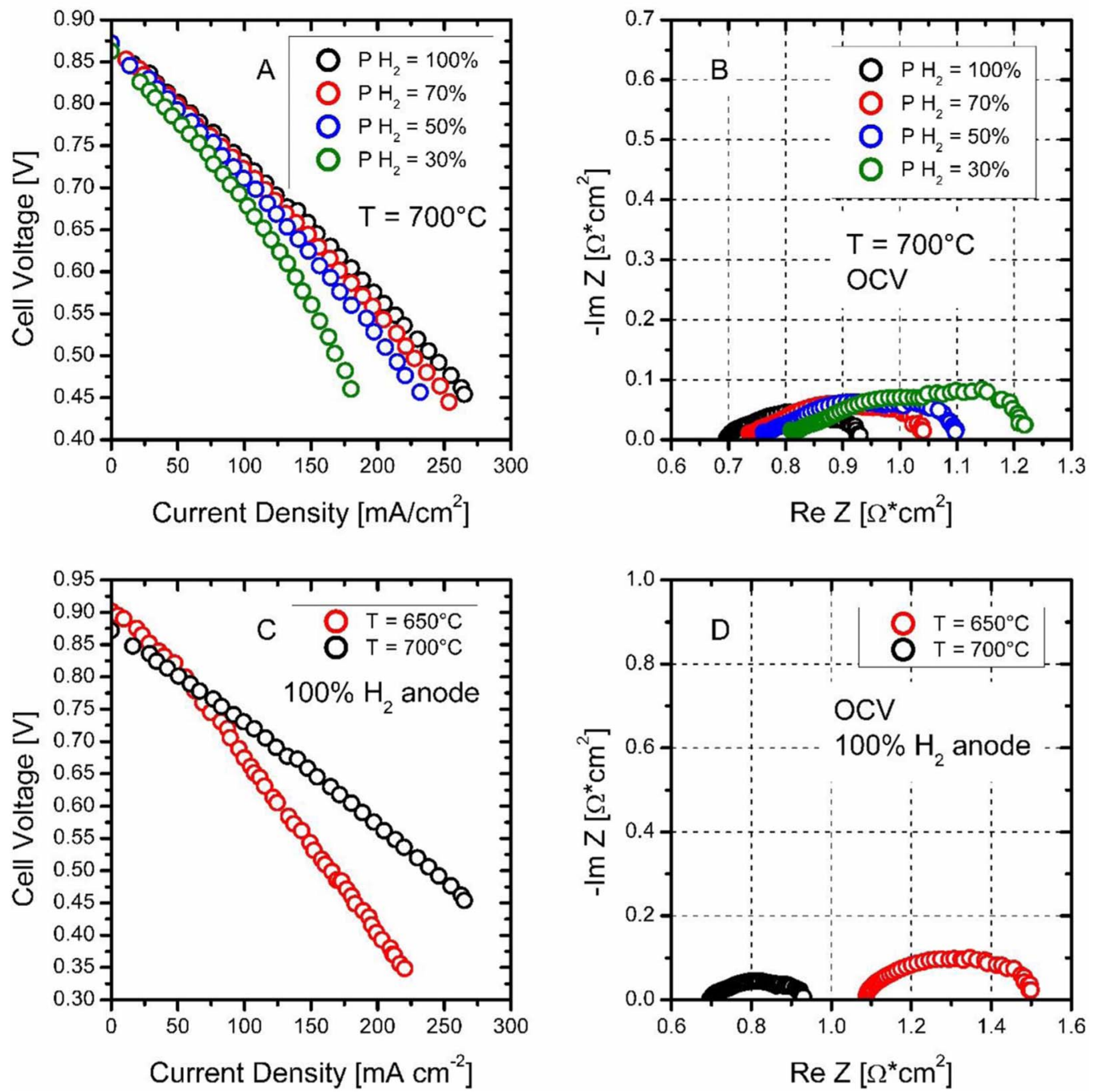

Figure 3. Panels A and B: experiments with $\mathrm{H}_{2} / \mathrm{N}_{2}$ mixtures at $700^{\circ} \mathrm{C}$. (o) $\mathrm{H}_{2}=100 \%$; (o) $\mathrm{H}_{2}=70 \%, \mathrm{~N}_{2}=30 \%$; (o) $\mathrm{H}_{2}=50 \%, \mathrm{~N}_{2}=50 \%$; (o) $\mathrm{H}_{2}=30 \%$, $\mathrm{N}_{2}$ $=70 \%$. Panels $\mathrm{C}$ and $\mathrm{D}$ : experiments at $650^{\circ} \mathrm{C}$ and $700^{\circ} \mathrm{C}$ with $100 \% \mathrm{H}_{2}$. (o) $\mathrm{T}=700^{\circ} \mathrm{C}$; (o) $\mathrm{T}=650^{\circ} \mathrm{C}$. Constant $3 \% \mathrm{H}_{2} \mathrm{O}$ humidification. Operating conditions for the EIS tests: open circuit, $10 \mathrm{kHz}-0.1 \mathrm{~Hz}$ frequency range, $10 \mathrm{mV}$ amplitude.

most important feature is the increasing value of the ohmic resistance measured with decreasing $\mathrm{H}_{2}$ partial pressure. Specifically, the ohmic resistance shifts from $0.696 \Omega \mathrm{cm}^{2}$ in pure hydrogen, to $0.736 \Omega \mathrm{cm}^{2}$ at $70 \% \mathrm{H}_{2}, 0.761 \Omega \mathrm{cm}^{2}$ at $50 \% \mathrm{H}_{2}$ and finally reaches $0.809 \Omega \mathrm{cm}^{2}$ at $30 \% \mathrm{H}_{2}$. This regular trend can neither be attributed to a non-perfect

\section{Table IV. OCV and electrolyte thickness for SDC- and GDC-based IT-SOFCs. All the data points refer to $700^{\circ} \mathrm{C}$ and humidified $\mathrm{H}_{2}$ feed conditions.}

\begin{tabular}{lll} 
OCV $[\mathrm{V}]$ & Electrolyte $[\mu \mathrm{m}]$ & Reference \\
\hline$S D C$ & & \\
0.900 & 1190 & 36 \\
0.846 & 380 & 37 \\
0.850 & 340 & 37 \\
0.810 & 80 & 38 \\
$G D C$ & & \\
0.876 & 400 & 39 \\
0.831 & 98 & 40 \\
0.775 & 35 & 41 \\
0.800 & 30 & 42
\end{tabular}

sealing of the cell, since repeated GC analyses on the exit streams confirmed that the gas composition corresponded to the desired target, nor to a variation of the cell temperature, which was held constant during the tests. Additionally, the measurements were fully reversible, meaning that the ohmic resistance was recovered when increasing the $\mathrm{H}_{2}$ amount from $30 \%$ to $100 \%$. Therefore, it can be concluded that the observed effect has a strictly electrochemical nature. Likely, it is related to the electrical conductivity of SDC, which varies with the reducing potential, and leads to a variation of the ohmic resistance. Further insight is provided by the model analysis of the results.

Experiments at $650^{\circ} \mathrm{C}$.- The polarization curve measured with humidified $\mathrm{H}_{2}$ is reported in Figure $3 \mathrm{C}$. The curve at $700^{\circ} \mathrm{C}$ is included as reference. Coherently with the nernstian driving force, the $\mathrm{OCV}$ value increases when the temperature decreases, from $0.87 \mathrm{~V}$ to 0.90 V. Compared to the curve at $700^{\circ} \mathrm{C}$, the ohmic resistance and the polarization resistance grow, leading to a lower performance, with reduction of the maximum extracted current to $210 \mathrm{~mA} \mathrm{~cm}^{-2}$. Except for the region close to the $\mathrm{OCV}$ (below $30 \mathrm{~mA} \mathrm{~cm}^{-2}$ ), the polarization curve is almost linear due to the predominant role of the ohmic losses. The impedance spectra at $650^{\circ} \mathrm{C}$ and $700^{\circ} \mathrm{C}$ are reported in Figure 3D. As expected, the ohmic resistance and the polarization resistance both increase, up to $1.05 \Omega \mathrm{cm}^{2}$ and $0.45 \Omega \mathrm{cm}^{2}$ respectively. 
Pd-Cu-CZ80/SDC/LSCF-GDC, $\mathrm{H}_{2} / \mathrm{N}_{2} 100-30 \%$ feed, $700^{\circ} \mathrm{C}$

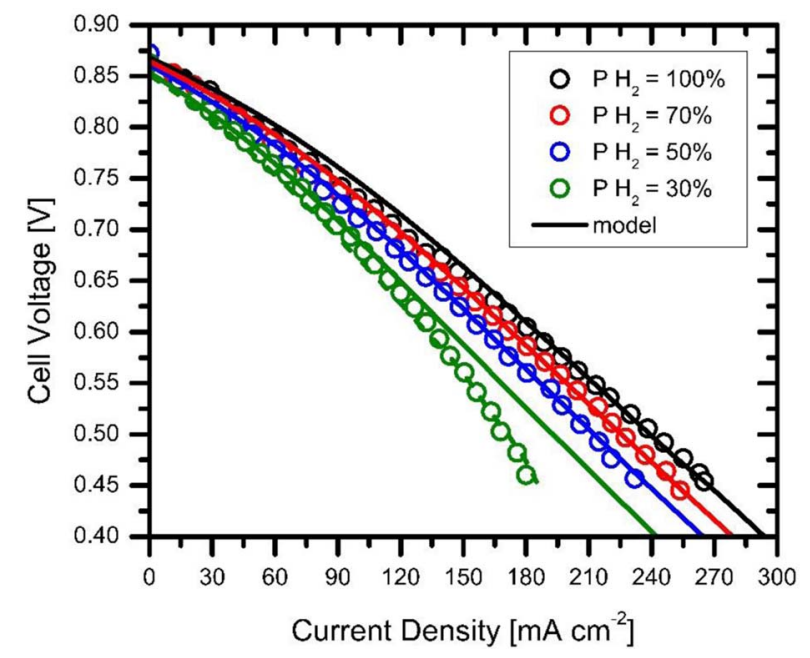

Figure 4. Comparison between experimental and simulated polarization curves for the experiments with $\mathrm{H}_{2} / \mathrm{N}_{2}$ mixtures at $700^{\circ} \mathrm{C}$. Lines are model simulations, symbols are data points.

Model simulations.-Polarization experiments at $700^{\circ}$ C.-Figure 4A shows the comparison between the simulated polarization curves and the experimental ones. The agreement is good in the whole current range. The OCV values are correctly predicted, and also the moderate decrease is captured. The curves at $100 \%, 70 \%$ and $50 \%$ $\mathrm{H}_{2}$ molar fraction are closely matched. In the case of $30 \% \mathrm{H}_{2}$, a close match is found up to $100 \mathrm{~mA} \mathrm{~cm}^{-2}$, while the simulation diverges at higher current, over-predicting the data points. On a traditional Nibased SOFC anode run with a $20 \% \mathrm{H}_{2} / \mathrm{N}_{2}$ mixture, ${ }^{43}$ Janardhanan and Deutschmann ${ }^{17}$ demonstrate that the assumption of a flux continuity boundary condition on the material balance equations allows for a better simulation of the high current region. In our model, the CSTR boundary condition is included, but still the simulations can be captured only by assuming more severe conditions for the diffusion, such as by increasing the anode tortuosity parameter to a value of 8 (dotted line in the plot). A refinement of this parameter enhances the description of the curve at low $\mathrm{H}_{2}$ concentration, with a limited influence on the other curves. This result confirms that the polarization behavior turns from ohmic-drop controlled to mass transfer controlled when the $\mathrm{H}_{2}$ concentration reaches $30 \%$ : however, such a high value also possibly indicates that other concurrent phenomena were active (i.e. anode partial re-oxidation), which increased the voltage loss. An additional explanation is possibly related to the occurrence of external mass transport limitations at the interface between the current collector and the recirculation gas volume, which the CSTR boundary condition (Eq. 20) cannot properly account for. On the one hand, the gas fluid dynamics between the electrode and the feed port is not ideal. On the other hand, the current collector can also act as an additional barrier for gas diffusion toward the porous anode: the current collector is indeed realized with a $150 \mu \mathrm{m}$ mesh fixed with silver paste on the whole surface, and it is certainly not zero-dimensional. Traces of this paste can be observed in Figure 1A, in form of a thin layer on the top of the cathode and at the bottom of the anode. Notwithstanding this mismatch, the simulations overall indicate that the model is reliable, especially in the low current density region $\left(<100 \mathrm{~mA} / \mathrm{cm}^{2}\right)$, where the impedance analysis is focused and where diffusion has no influence.

Impedance experiments at $700^{\circ}$ C.- The comparison between simulated and experimental impedance spectra at OCV is reported in Figure 5 in four distinct Nyquist plots. The corresponding Bode plots are shown in Figure 6. For all the spectra, the model predicts fairly well the ohmic resistance and the polarization resistance, and a good qual- itative agreement is found for the shape, the position and the number of impedance features. First of all, and most importantly, the spectra follow the progressive increase of the ohmic resistance, confirming the adequacy of the physical description of the cell. At the best of our knowledge, this shift effect has not been previously simulated with a distributed charge-transfer model based on conservation equations. Specifically, the predicted resistance passes from $0.721 \Omega \mathrm{cm}^{2}$ in pure hydrogen, to $0.754 \Omega \mathrm{cm}^{2}$ at $70 \% \mathrm{H}_{2}, 0.785 \Omega \mathrm{cm}^{2}$ at $70 \% \mathrm{H}_{2}$, and reaches $0.831 \Omega \mathrm{cm}^{2}$ at $30 \% \mathrm{H}_{2}$. The overestimation of the experimental resistances is systematic, but largely acceptable since it maintains between $2 \%$ and $3.6 \%$ in all the conditions. Such a small difference can be accepted considering that the conductivity parameters of the SDC electrolyte are not assumed as adjustable, although most of them are not directly measured. The simulated spectra closely predict the polarization resistance, with a deviation from the experimental value never larger than $\pm 2 \%$ observed only at $70 \% \mathrm{H}_{2}$. With respect to the features of the impedance curves, the spectra show two main arcs, a first one located at high frequencies (from $1 \mathrm{kHz}$ to $10 \mathrm{~Hz}$ ) and a second one at low frequencies (form $10 \mathrm{~Hz}$ to $10 \mathrm{mHz}$ ), which are also reproduced by the simulations. The high frequency arc is associated to the activity of the cathode, while the second one to the activity of the anode. The flattened shape of the first arc is partially reproduced by the model, while limited discrepancies arise with the second arc, which is rounder than the measured one. A better shape-agreement could be in principle found by application of the DRT approach ${ }^{44,45}$ (beyond the scope of this work) or by re-estimation of the impedance spectra via the introduction of constant phase elements ${ }^{46}$ (which would increase the number of unknown fitting parameters). The model does not include the distribution of characteristic times: each phenomenon occurs with a single-valued characteristic time constant, and the depressed character of the arc cannot be mirrored.

Figure 6 shows the Bode plot representation of the impedance spectra. Two main peaks are observed, one at $\sim 15 \mathrm{~Hz}$ and associated to the cathode, the other at $\sim 0.1 \mathrm{~Hz}$, which grows as the $\mathrm{H}_{2}$ molar fraction decreases and which is related to the anode (Sensitivity analysis). A third smaller shoulder is also noted around $500 \mathrm{~Hz}$, which is possibly due to the SDC/GDC interface at the cathode. The model predictions follow the experimental trends, with better agreement at high frequencies, and tolerable overestimation at low frequencies. This discrepancy reflects the difference in the simulations of the imaginary part of the spectra. The Bode plots allow to tune the double layer capacitance parameters. When fitting these parameters, consistency with the literature values is privileged $\sim 100 \mathrm{~F} \mathrm{~m}^{-2}$ are found at the anode, in line with the estimates by Bertei et al. ${ }^{20}$ for Ni/YSZ interfaces, and $\sim 150 \mathrm{~F} \mathrm{~m}^{-2}$ are calculated at the cathode, which is higher than the value evaluated with the correlation by Yurkiv et al. ${ }^{47}$ for the LSCF/GDC interface, but still in the order of magnitude proposed in the literature. ${ }^{48}$ The absence of an additional capacitance does not allow to describe the third, minor arc, whose impact is however negligible in the cell performance. Notwithstanding these drawbacks, the Bode plots provide a reasonable picture of the impedance process.

The model simulations are overall satisfactory, considering that they are obtained by adjusting a limited number of parameters, that they span over a wide range of $\mathrm{H}_{2}$ molar fractions and that they simultaneously reconcile both polarization and EIS measurements. Most importantly, the key features of the experimental investigation are captured, namely the non-Nernstian values of the OCV and the shift of the ohmic resistance.

Sensitivity analysis. - A clear association between the features of the impedance spectra and the electrodes behavior is obtained with a sensitivity analysis on the most important model parameters, and by deconvoluting the simulated spectra and Bode curves (Figure 7). The experiment performed at $700^{\circ} \mathrm{C}$ and $30 \% \mathrm{H}_{2}$ is set as reference. The results are representative of all the other cases. The sensitivity analysis takes into account structural (thickness, porosity, tortuosity and particle diameter), kinetic (exchange current density) and transport properties (effective ionic and electronic conductivity) of the electrodes, as well as the conductivity and the thickness of the 


\section{Pd-Cu-CZ80/SDC/LSCF-GDC, $\mathrm{H}_{2} / \mathrm{N}_{2} 100-30 \%$ feed, $700^{\circ} \mathrm{C}$}

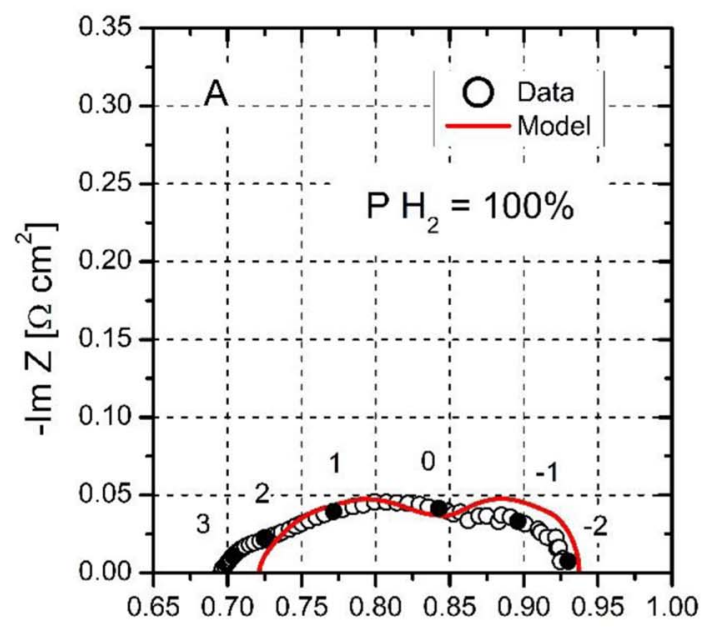

$\operatorname{Re} Z\left[\Omega \mathrm{cm}^{2}\right]$

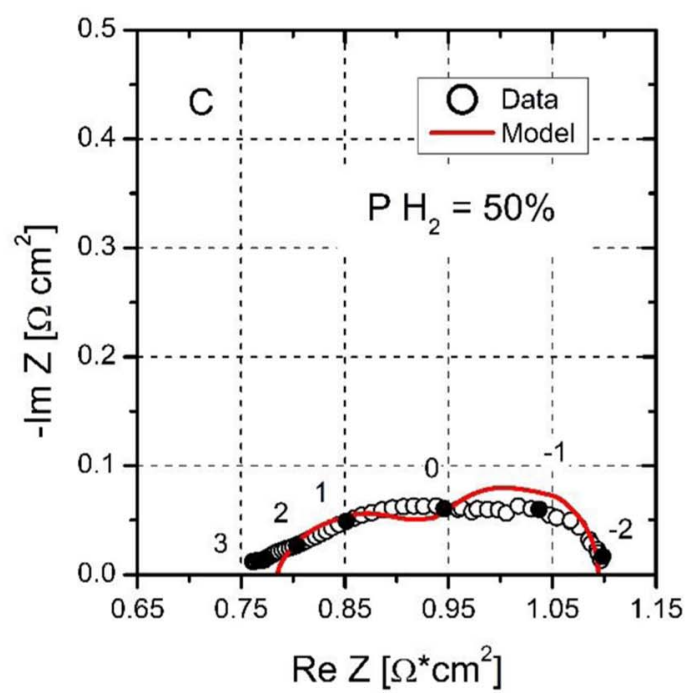

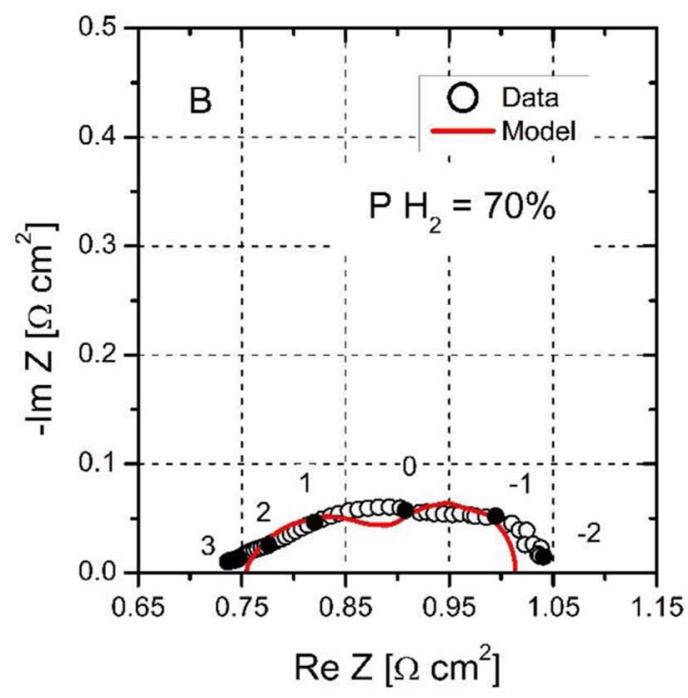

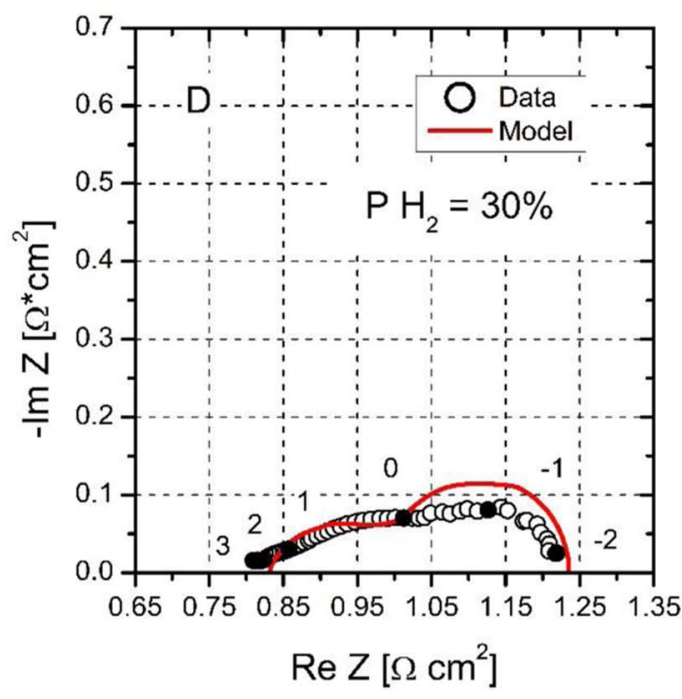

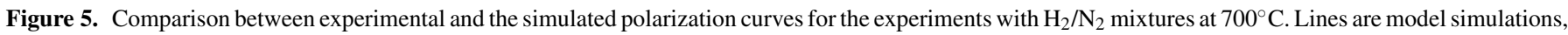

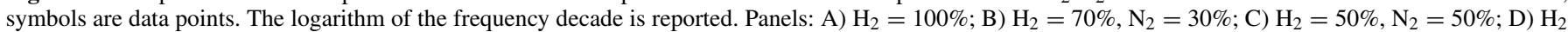
$=30 \%, \mathrm{~N}_{2}=70 \%$. Constant $3 \% \mathrm{H}_{2} \mathrm{O}$ humidification. Operating conditions: open circuit, $10 \mathrm{kHz}-0.1 \mathrm{~Hz}$ frequency range, $10 \mathrm{mV}$ amplitude.

electrolyte. A sensitivity parameter (SP) is defined with respect to the polarization resistance $\mathrm{R}_{\mathrm{Pol}}$ and a variation of $\pm 10 \%$ of each parameter $\left(\Delta R_{P o l} / R_{P o l} / 0.1\right)$. A negative $S P$ value indicates a decrease of $\mathrm{R}_{\mathrm{Pol}}$. Due to its thin thickness, the morphological properties of the cathode negligibly influence the polarization resistance. With respect to the kinetic and conductivity parameters, the cathode has almost no influence and does not hinder the cell activity. The porosity and the tortuosity of the anode are nearly insensitive: it is important to note that, in order to isolate the effect of the porosity on mass diffusion, the SP is evaluated at fixed active surface area $a_{v}$ and fixed effective conductivities. This result indicates that mass transport is not limiting the cell behavior at $\mathrm{OCV}$, despite the low $\mathrm{H}_{2}$ concentration. Differently, an increase of the anode thickness has a positive influence on $\mathrm{R}_{\mathrm{Pol}}$. Similar results are also reported by Yurkiv et al. ${ }^{47}$ and Nicolella et al., ${ }^{49}$ and suggest that the thickness of the anode is smaller than the optimal electrochemically active threshold. Hence, an enlargement proves beneficial. The particle diameter directly determines the active surface area: a decrease leads to lower $R_{P o l}$ thanks to larger $a_{v}$. A strong sensitivity is evidenced, which proves that the impedance is mostly determined by the anodic kinetics. Coherently with this result, the same SP value is found in the case of the exchange current density of the $\mathrm{H}_{2}$ electro-oxidation. The ionic conductivity plays a limited role, while the electronic conductivity none. A strong sensitivity is however found on the electronic and the ionic conductivity of the electrolyte, given that these properties directly determine the density of the leakage current, and in turn the extent of the anodic polarization at OCV.

A simple deconvolution of the EIS curve and of the Bode plot (Figures 7B and 7C) helps in interpreting the spectra. The cathode contribution is evidenced by switching-off the double layer capacitance and the kinetics of the anode, and vice versa the anode contribution is highlighted by quitting the double layer capacitance and the kinetics of the cathode. In both cases, the calculation is carried out by assigning the correct voltage $(0.85 \mathrm{~V})$ and leakage current $(50$ $\mathrm{mA} \mathrm{cm}{ }^{-2}$ ) to the cell. The result shows that the cathode contribution is smaller and located in the high frequency range (peak at $15 \mathrm{~Hz}$ ). The shape can be associated with a gas-diffusion impedance coupled with charge transfer reaction. The dominant contribution of the anode is observed in the low frequency region (peak at $0.25 \mathrm{~Hz}$ ). Similar arcs are presented and discussed for standard Ni-YSZ anodes ${ }^{19,20,49}$ 
Bode Plot Pd-Cu-CZ80/SDC/LSCF-GDC T $=700^{\circ} \mathrm{C}$

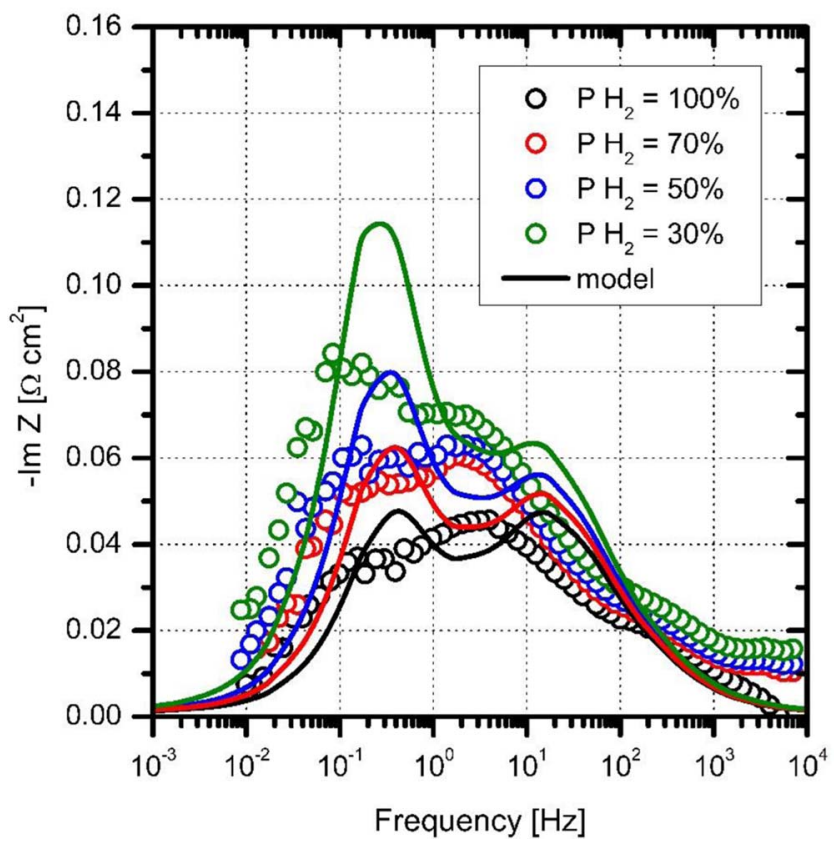

Figure 6. Bode plot for the EIS experiments at $700^{\circ} \mathrm{C}$. Symbols are data points, lines are model simulations.

and are representative of a reaction process driven by the distributed charge transfer at the gas/solid interface. A picture thus emerges from these results, where the impedance is governed by the anodic polarization, which is activated by the draw of leakage current from the electrolyte: the anode kinetics are slow and constitute the main share of the polarization resistance.

These basic associations are supported by the results of an equivalent circuit model. A simple $R_{\text {ohm }}(R Q)_{\text {cat }}(R Q)_{a n 1}(R Q)_{\text {an2 }}$ circuit allows to fairly describe the experimental spectra at $700^{\circ} \mathrm{C}$. In the circuit, $R_{\text {ohm }}$ is associated to the electrolyte, the (RQ) cat element represents the cathode, and the two RQ elements $\left(R_{a n 1}\right.$ and $\left.R Q_{a n 2}\right)$ describe the anode. ${ }^{50}$ The introduction of two RQ elements mirrors the shape of the anode spectra simulated by the physical-based model (Figure 7B), which shows two overlapping arcs. This choice has two consequences: only the sum of the resistances $\left(R_{a n}\right.$ tot $\left.=R_{a n 1}+R_{a n 2}\right)$ can be

\begin{tabular}{|c|c|c|c|c|}
\hline \multicolumn{5}{|c|}{ Rohm } \\
\hline & $100 \% \mathrm{H}_{2}$ & $70 \% \mathrm{H}_{2}$ & $50 \% \mathrm{H}_{2}$ & $30 \% \mathrm{H}_{2}$ \\
\hline \multicolumn{5}{|l|}{$E C M$} \\
\hline $\mathrm{R}_{\mathrm{ohm}}$ & 0.693 & 0.733 & 0.747 & 0.771 \\
\hline $\mathrm{R}_{\mathrm{cat}}$ & 0.093 & 0.113 & 0.118 & 0.124 \\
\hline$v_{\text {cat }}$ & 49.0 & 45.6 & 48.7 & 49.6 \\
\hline $\mathrm{R}_{\mathrm{an}} 1$ & 0.096 & 0.106 & 0.144 & 0.184 \\
\hline$v_{\text {an }} 1$ & 1.97 & 2.12 & 2.43 & 2.03 \\
\hline $\mathrm{R}_{\mathrm{an}} 2$ & 0.047 & 0.086 & 0.096 & 0.129 \\
\hline$v_{\text {an }} 2$ & 0.097 & 0.131 & 0.097 & 0.088 \\
\hline $\mathrm{R}_{\mathrm{an} \text { tot }}$ & 0.143 & 0.192 & 0.241 & 0.313 \\
\hline \multicolumn{5}{|l|}{ Model } \\
\hline $\mathrm{R}_{\mathrm{ohm}}$ & 0.721 & 0.754 & 0.785 & 0.831 \\
\hline $\mathrm{R}_{\mathrm{cat}}$ & 0.087 & 0.091 & 0.096 & 0.101 \\
\hline $\mathrm{R}_{\mathrm{an}}$ & 0.129 & 0.168 & 0.213 & 0.303 \\
\hline
\end{tabular}

compared to the anode resistance simulated by the model $\left(\mathrm{R}_{\mathrm{an}}\right)$; the equivalent capacitances estimated via fitting cannot be directly compared to the double layer capacitances included in the model for the electrode/electrolyte interface. The fitted resistances and characteristic frequencies $(v)$ are reported in Table V. A fair agreement between ECM and model predictions is achieved and the qualitative trends are respected. All the resistances grow when $\mathrm{H}_{2}$ decreases, and the growth is more pronounced for the anode resistance, which doubles. Quantitatively, the cathode resistance shows the largest deviation $(+20 \%)$. A reason for this is possibly the closer prediction of the ohmic resistance, which is directly fitted and causes a redistribution of the offset located mainly on the cathode. The characteristic frequencies are also reasonably captured, both in trend and order of magnitude, in agreement with the model predictions and the experiments.

Validation of the model parameters.-The simulations of the experiments at $650^{\circ} \mathrm{C}$ are reported in Figure 8. Although restricted to a single compositional value and one temperature level, this data set can be used to preliminary validate the parameters calibrated at $700^{\circ} \mathrm{C}$, since the calculations are performed with a predictive approach. A
Sensitivity Analysis

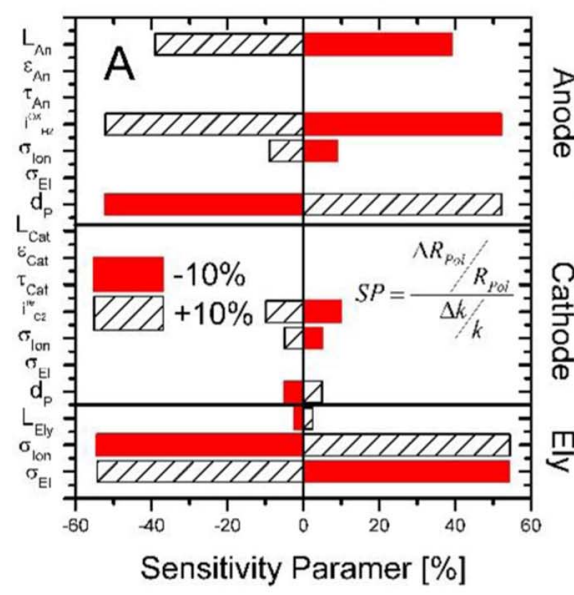

EIS deconvolution

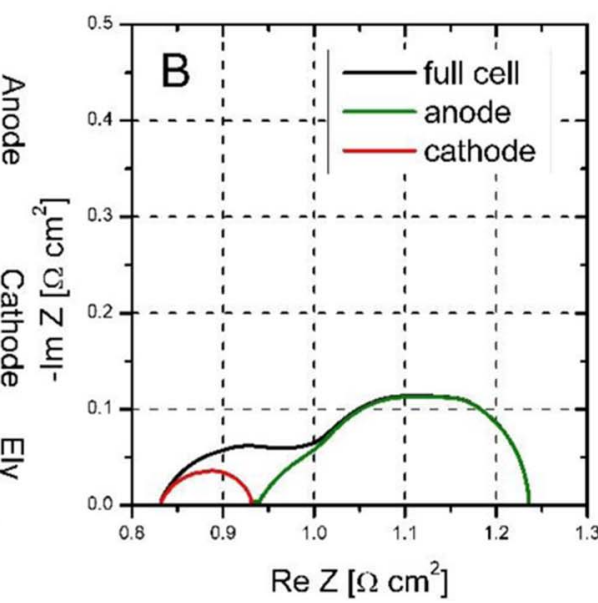

Bode plot deconvolution

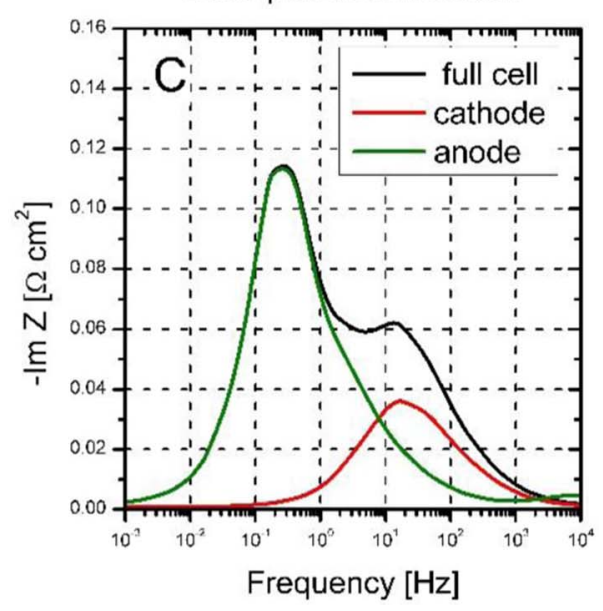

Figure 7. Sensitivity analysis on the simulated EIS spectrum at $700^{\circ} \mathrm{C}$ and $30 \% \mathrm{H}_{2}$. Panels: A) Sensitivity analysis on the main model parameters; B) Deconvolution of the impedance spectrum; C) Deconvolution of the Bode plot. (-) full IT-SOFC; (-) cathode contribution; (-) anode contribution. 


\section{Pd-Cu-CZ80/SDC/LSCF-GDC, humidified $\mathrm{H}_{2}, 650^{\circ} \mathrm{C}$}
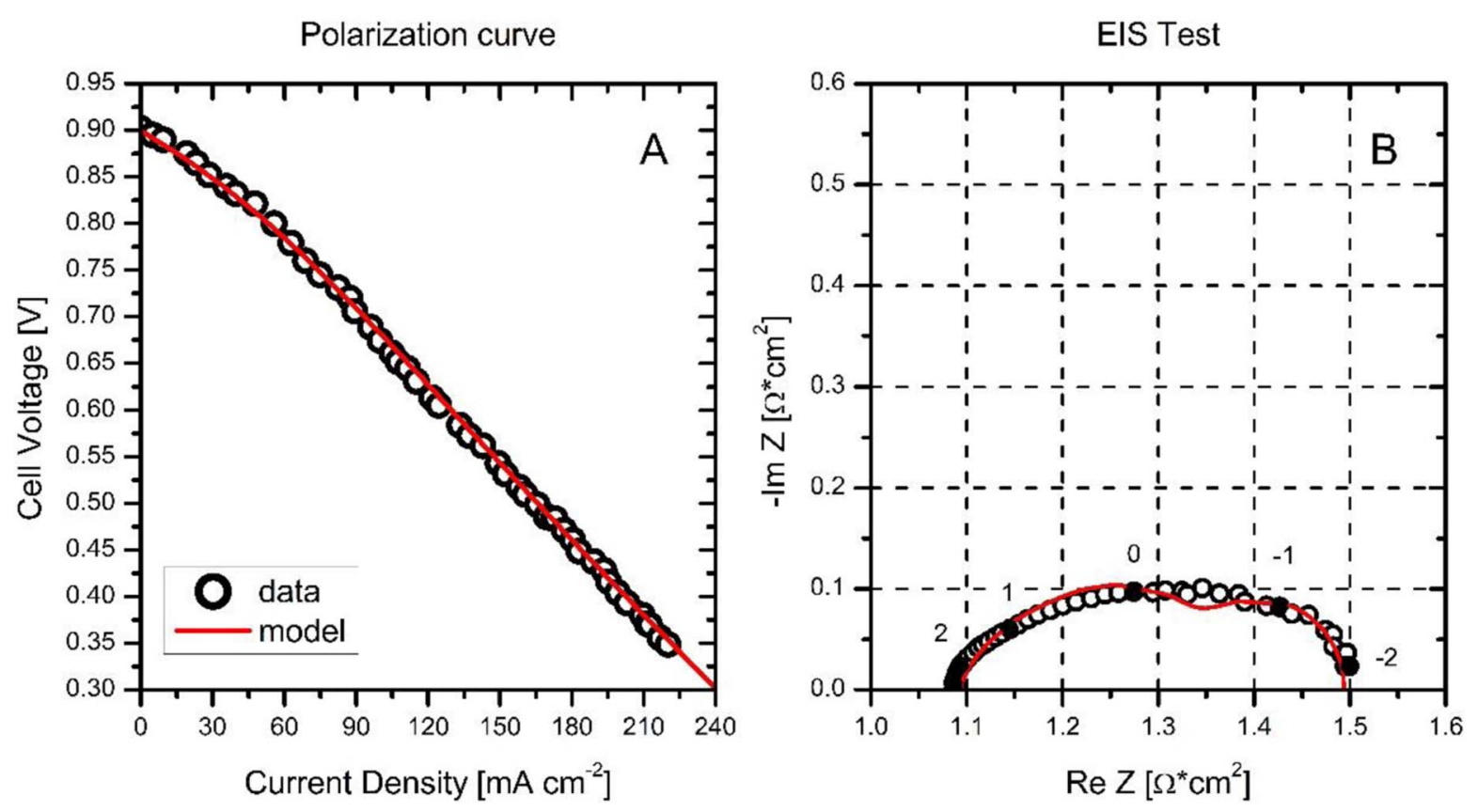

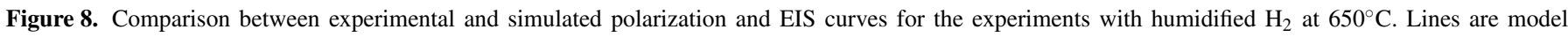
simulations, symbols are data points.

remarkable agreement is found in the entire current range of the polarization curve (Figure 8A): the OCV increase is captured and the calculated current/voltage values overlap with the experimental ones. A good match is visible also in the impedance curve (Figure $8 \mathrm{~B})$, where both the ohmic resistance $\left(1.09 \Omega \mathrm{cm}^{2}\right)$ and the polarization resistance $\left(1.49 \Omega \mathrm{cm}^{2}\right)$ are predicted with less than $1 \%$ error. The simulated curve follows the shape of the spectrum, with a minor deviation around $0.5 \mathrm{~Hz}$, where a depression between the two arcs is predicted. A better description can be achieved by decreasing the capacitances and introducing a dependence on the temperature: such a dependency can be confidently neglected and would introduce additional fit parameters. Considering that the behavior of the IT-SOFC at $650^{\circ} \mathrm{C}$ is dominated by the leakage current effect in the high voltage range $(0.9-0.8 \mathrm{~V})$ and by the ohmic drop at lower voltage, these results further confirm that the main effects due to the electrolyte are correctly accounted for. As well, the choice of the ionic and electronic conduction parameters (Table II) and the extraction of the kinetic parameters of the electrodes (Table III) appear to be reliable. As a matter of fact, the numerical results can be confidently used to rationalize the main observed kinetic effects.

\section{Discussion}

Once validated, the model is applied to simulate the evolution of parameters that are not directly measured along the cell, and to provide insight into the main features of the IT-SOFC examined. The backbone of the phenomena highlighted in the section of results is discussed with more detail.

Electronic leakage current.-Figure 9A shows the electronic leakage current density computed at the different feed compositions, as a function of the current extracted from the cell. The leakage current decreases when the extracted current increases, implying that OCV gives rise to the highest leakage current. The simulations also verify that the leakage current increases with the $\mathrm{H}_{2}$ molar fraction in the feed. A better insight is provided by looking at the axial profiles of both the electronic leakage current and the ionic current along the whole cell thickness. The profiles are proposed for three cases: at OCV (Figure 9B), under an extracted current density of $100 \mathrm{~mA} \mathrm{~cm}^{-2}$ (Figure 9C), and under an extracted current density of $300 \mathrm{~mA} \mathrm{~cm}^{-2}$ (Figure $6 \mathrm{D})$. In the plots, the anode current collector is located at $\mathrm{z}=0$, the cathode current collector at $\mathrm{z}=0.57 \mathrm{~mm}$, and the electrolyte position goes from $\mathrm{z}=0.15 \mathrm{~mm}$ to $\mathrm{z}=0.53 \mathrm{~mm}$. At OCV, the electrolyte is crossed by a flow of oxide ions from the cathode to the anode (positive ionic current) and by a flow of electrons from the anode to the cathode (negative electronic leakage current). In this situation, no net current is extracted from the cell, although the electrodes are interested by flow of charges: such a flow is strictly of chemical nature, and allows the electrolyte material to remain stable. The electrolyte is therefore characterized by a flow of ions also in the absence of a net current load, that is, when the cell is idle.

When a load of $100 \mathrm{~mA} \mathrm{~cm}{ }^{-2}$ is considered, some interesting implications emerge. First, the electronic current is supplied to the electrodes and is gradually converted into ionic current in a region called electrochemically active thickness (EAT). Both the anodic and the cathodic EAT extends over the whole electrode, which results entirely electrochemically active. The charge transfer process is not confined just into a short region nearby the electrode/electrolyte interface, suggesting in turn, that the electrodes are not optimally dimensioned. This result also explains why limited current densities are measured in the cell. Aside of the extension of the charge-transfer zone, it is important to mention that the EAT now comprises a zone, close to the electrolyte, where the net electronic current has a negative orientation, given that the leakage effect still prevails over the electrochemical conversion. As a matter of fact, in the electrolyte the value of ionic current density is higher than the value of the maximum extracted current: $100 \mathrm{~mA}$ $\mathrm{cm}^{-2}$ at the current collector originate $125 \mathrm{~mA} \mathrm{~cm}^{-2}$ in the electrolyte. In other words, on the one hand, owing to the redox cycle inside Ceria, an additional and co-current flow of oxide ions is present in the electrolyte. On the other hand, there is still a negative zone attributed to the leakage current. This behavior is not noted when a higher load of $300 \mathrm{~mA} \mathrm{~cm}^{-2}$ is applied, due to the fact that the leakage current density becomes null when enough current density is extracted, and 
Electronic Current

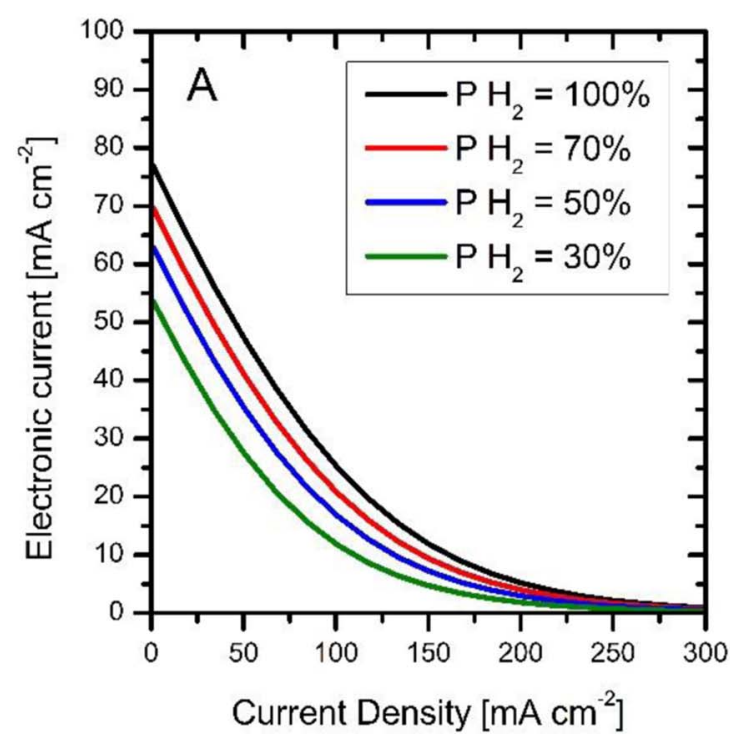

$100 \mathrm{~mA} \mathrm{~cm}^{-2}$

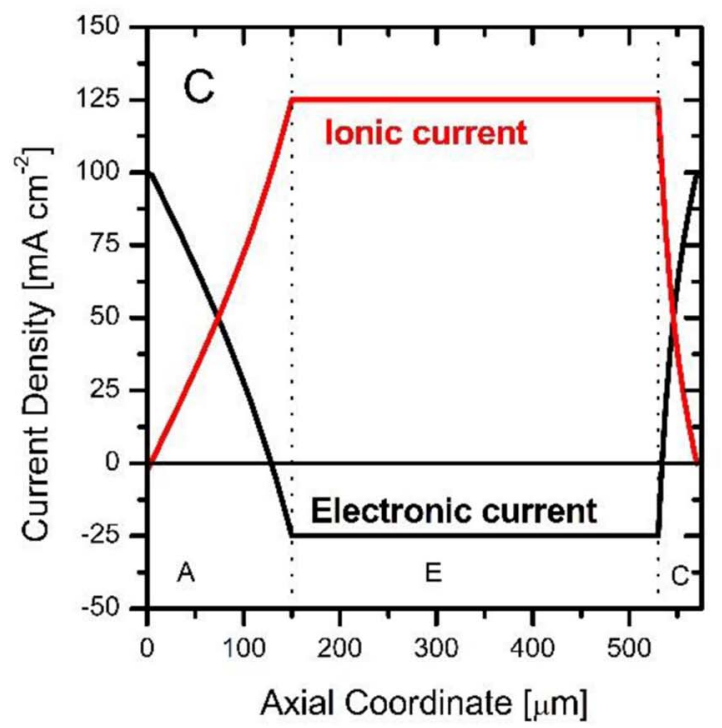

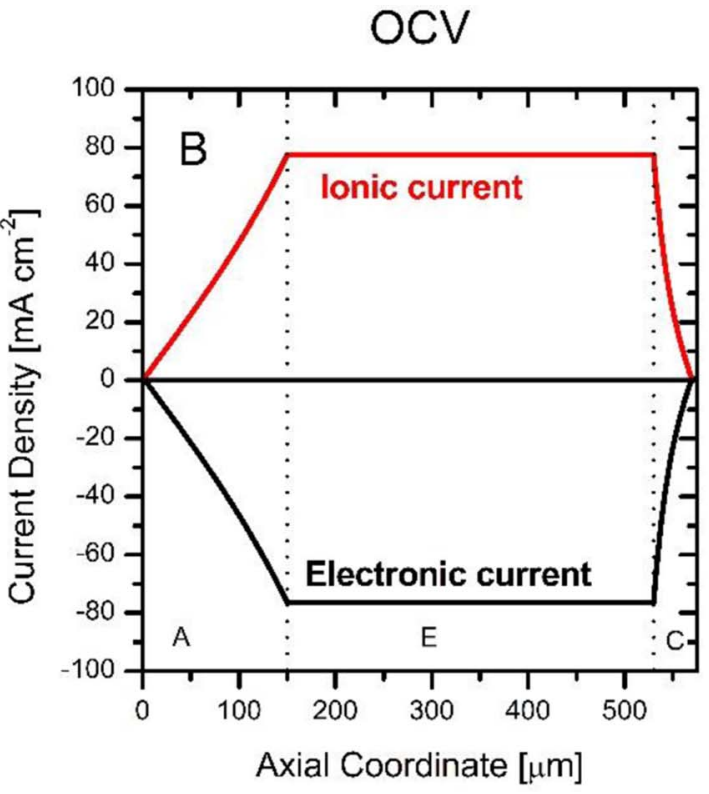

$300 \mathrm{~mA} \mathrm{~cm}^{-2}$

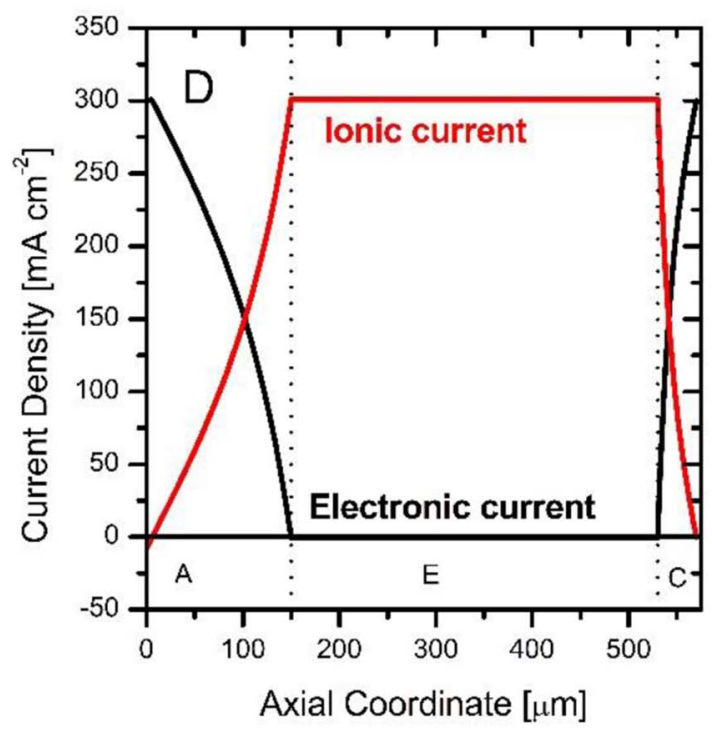

Figure 9. Model simulations. A) Leakage current density at different composition of the feed mixture. Ionic and electronic current density profiles along the cell thickness at: B) OCV; C) $\mathrm{i}=100 \mathrm{~mA} \mathrm{~cm}^{-2}$; D) $\mathrm{i}=300 \mathrm{~mA} \mathrm{~cm}^{-2}$. Anode (A), electrolyte (E), cathode (C).

the whole electronic current introduced at the electrodes converts into ionic current in the electrolyte. As effectively summarized by Dalslet et al., ${ }^{3}$ the electrolyte becomes a better (ion-transferring) electrolyte at increasing the current load.

Ohmic resistance at $\boldsymbol{O C V}$.-Focusing on the model analysis of impedance spectra of Ceria-based MIEC electrolytes, the group of Haile $^{8,9}$ demonstrated that the measured ohmic resistance (reported as $R_{\infty}$, i.e. the first intercept of the impedance curve with the real axis of the Nyquist plot at high frequency) depends on the electrical resistance of the electrolyte. $R_{\infty}$ is defined by two contributions in parallel, one due to the ionic resistance $\left(\mathrm{R}_{\text {ion }}\right)$ and the other due to electronic resistance $\left(\mathrm{R}_{\mathrm{el}}\right)$ of the MIEC electrolyte.

$$
\frac{1}{R_{\infty}}=\frac{1}{R_{\text {ion }}}+\frac{1}{R_{e l}}
$$

The measured ohmic resistance $\mathrm{R}_{\infty}$ can be easily compared to the ionic resistance, as follows:

$$
R_{\infty}-R_{i o n}=-\frac{R_{i o n}^{2}}{R_{i o n}+R_{e l}}
$$

The difference between the measured ohmic resistance and the ionic resistance has a negative value, which means that $R_{\infty}<R_{\text {ion }}$. Depending on the electronic resistance of the MIEC electrolyte, the ohmic resistance $R_{\infty}$ assumes a certain value lower than the ionic resistance of the electrolyte. Equation 28 also shows that, if $R_{\mathrm{el}}$ increases (tending to an electronic-insulating condition), the measured ohmic resistance tends to $\mathrm{R}_{\text {ion }}$. This latter situation corresponds to the typical case of purely electronic insulating electrolytes (infinite $\mathrm{R}_{\mathrm{el}}$ ). With respect to the dependencies of the two terms, the electronic resistance of the MIEC electrolyte at constant temperature is a function of oxygen partial pressure at anode/electrolyte interface. The 


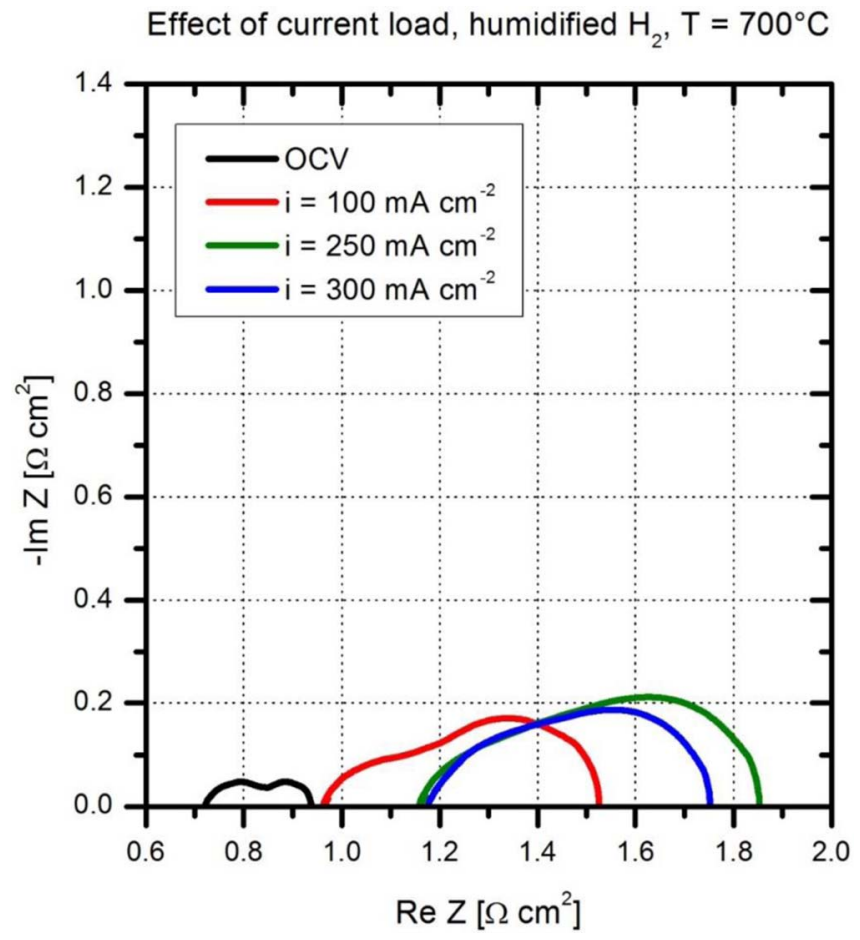

Figure 10. Simulated EIS spectra of the humidified $\mathrm{H}_{2}$ mixture at different current loading. (-) OCV; (-) $\mathrm{i}=100 \mathrm{~mA} \mathrm{~cm}{ }^{-2}$; (-) $\mathrm{i}=250 \mathrm{~mA} \mathrm{~cm}^{-2}$; $(-) \mathrm{i}=300 \mathrm{~mA} \mathrm{~cm}^{-2}$.

following relationship holds for $\mathrm{R}_{\mathrm{el}}$ :

$$
R_{e l}=\left[\sigma_{e l}^{0} \cdot\left(p_{O_{2}}^{0}\right)^{-1 / 4}\right]^{-1}=\left(\sigma_{e l}^{0}\right)^{-1} \cdot\left(\frac{\left.P_{\mathrm{H}_{2} O}\right|_{\text {an } / e l y}}{\left.P_{\mathrm{H}_{2}}\right|_{\text {an/ely }} \cdot k_{\mathrm{H}_{2} O x}^{e q}}\right)^{1 / 2}
$$

In light of these equations, it is easy to rationalize the shift of the impedance curves observed at decreasing $\mathrm{H}_{2}$ partial pressure (Figure 5). $\mathrm{A} \mathrm{H}_{2}$ partial pressure equal to $100 \%$ corresponds to the lowest electronic resistance of the electrolyte and to the lowest measured ohmic resistance. By decreasing the amount of $\mathrm{H}_{2}$ and moving to a less reducible anodic atmosphere, the electronic resistance of the electrolyte increases, and the ohmic resistance of the impedance spectrum moves toward the right side of the real axis.

Ohmic resistance under load conditions.-In light of the dependence of the ohmic resistance on the $\mathrm{H}_{2}$ partial pressure, it is interesting to verify the EIS behavior in the presence of an extracted current, which decreases the amount of $\mathrm{H}_{2}$ in favor of $\mathrm{H}_{2} \mathrm{O}$. The shift of the ohmic resistance under load conditions is explored by simulating the impedance spectra under humidified $\mathrm{H}_{2}$ feed. Figure 10 presents the spectra calculated under four different load conditions including: no load (OCV), $100 \mathrm{~mA} \mathrm{~cm}^{-2}, 250 \mathrm{~mA} \mathrm{~cm}^{-2}$ and $300 \mathrm{~mA} \mathrm{~cm}^{-2}$. The results clearly show that, as a higher current is extracted from the cell, the ohmic resistance progressively increases starting from $0.717 \Omega$ $\mathrm{cm}^{2}$ and finally setting to a value of $1.17 \Omega \mathrm{cm}^{2}$. This value corresponds to the ohmic resistance of the $380 \mu \mathrm{m}$ electrolyte at $700^{\circ} \mathrm{C}$ (Table II). These results indicate that, at sufficiently high current, the conversion of $\mathrm{H}_{2}$ is enough to almost quit the electronic conduction of the electrolyte. Recalling that the cell voltage is a function of the ionic current density and of the ion transfer resistance, and making use of the relationship proposed by Dalslet et al., ${ }^{3}$ the observed behavior is also theoretically explained.

$$
V_{\text {cell }}=E_{\text {rev }}-\eta_{\text {act }}^{\text {an }}\left(i_{\text {ion }}^{\text {ely }}\right)-\eta_{\text {act }}^{\text {cat }}\left(i_{\text {ion }}^{\text {ely }}\right)-R_{\text {ion }} \cdot i_{\text {ion }}^{\text {ely }}
$$

By substituting the conservation equation (Eq. 16) in Equation 31, the cell impedance can be written as the derivative of the voltage with respect to the extracted current load, and expressed in terms of the electronic leakage current.

$$
Z(\omega)=\frac{\partial V_{\text {cell }}}{\partial i_{\text {cell }}}=R_{\text {pol }}^{a n}+R_{\text {pol }}^{\text {cat }}+R_{\text {ion }} \cdot\left(1-\frac{\partial i_{\text {el }}^{e l y}}{\partial i_{\text {cell }}}\right)
$$

Equation 32 clarifies in simple terms the relationship between the cell impedance $\mathrm{Z}$ and the electronic leakage current ( $\mathrm{i}^{\mathrm{ely}} \mathrm{el}$ ), and readily provides the reason for the shift of the ohmic resistance. Indeed, with reference to Figure 9A, when the cell current approaches sufficiently high values, the electronic leakage current tends to zero with a null derivative (Eq. 33) and the ohmic resistance tends to the ionic one. After a certain level of extracted current, the effect vanishes and the ionic resistance prevails. On opposite, a large value of the derivative is found when approaching the OCV condition, which heavily reduces the ohmic resistance term.

$$
i_{\text {cell }} \rightarrow+\infty \Rightarrow \frac{\partial i_{e l}^{e l y}}{\partial i_{\text {cell }}} \rightarrow 0
$$

In order to provide an experimental proof for the ohmic resistance translation under load, additional experiments were performed on an SDC electrolyte-supported IT-SOFC, similar to the main one, but with different anode composition. A Cu-Ni/SDC/LSCF-GDC cell with a $80 / 20 \mathrm{~mol} / \mathrm{mol} \mathrm{Cu} / \mathrm{Ni}$ anode was prepared by infiltration of the porous SDC scaffold ( $290 \mu \mathrm{m}$ anode, $470 \mu \mathrm{m}$ electrolyte, $40 \mu \mathrm{m}$ cathode). Polarization and impedance measurements were carried out at $700^{\circ} \mathrm{C}$ with a $20 \% \mathrm{H}_{2}$ and $80 \% \mathrm{~N}_{2}$ mixture. Figure 11 reports the polarization curve (panel a) and the EIS spectra collected under OCV and $0.4 \mathrm{~V}$ load (panel b). This voltage level was specifically chosen to evidence the shift of the impedance spectra, given that it belongs to a region where the purely ionic resistance starts prevailing. Notwithstanding the lower polarization performance, due to the non-optimal configuration of the IT-SOFC and to the thicker electrolyte, the results clearly provide the required proof: the ohmic resistance value under load is higher than that measured at OCV, consistently with the theoretical derivation.

Polarization behavior.-An inspection of Figure 4 reveals that the examined IT-SOFCs have a particular polarization profile: a concave voltage decay is observed in the low current region, which is followed by a steady linear decrease. The same behavior is also found with GDC-based cells, ${ }^{11}$ and can be taken as a fingerprint of IT-SOFCs with MIEC electrolytes. This kind of profile completely differs from that of standard YSZ-based cells, wherein the shape of the initial voltage decay is either linear or exponential (with convex concavity) according to the Butler-Volmer dependency. In order to reconcile the difference, a detail on the contributions that build up the polarization curves is presented in Figure 12A, with reference to the simulations at $100 \% \mathrm{H}_{2}$. The cell behavior is determined by the activation polarization of the anode and by the ohmic loss of the electrolyte. The cathodic activation polarization contributes to a minor extent, while the concentration polarization (included in the Nernst potential, Eq. 9) has a limited role. The anodic activation loss prevails until $190 \mathrm{~mA} \mathrm{~cm}^{-2}$, then the ohmic loss of the electrolyte becomes larger. The balance between these two losses originates the shape of the polarization profile at low current density. The curvature is associated to the evolution of the ohmic loss term $\left(\mathrm{R}_{\text {ion }} * \mathrm{i}^{\text {ely }}{ }_{\text {ion }}\right.$ in Eq. 31$)$, which varies more than linearly. This dependence stems from the ionic current density in the electrolyte ( $\mathrm{i}^{\mathrm{ely}}$ ion $)$, which grows exponentially up to an asymptote (i.e. the total extracted current density) due to the exponential decay of the electronic leakage current (Figure 9A). The simulations of Figure 12A also suggest that such a pronounced curvature is a consequence of the slow anode kinetics, which causes the activation overpotential to reach the Tafel-like linear branch already when a current density of $80 \mathrm{~mA}$ $\mathrm{cm}^{-2}$ flows in the electrolyte. As a matter of fact, depending on the extent of the electrode polarization and of the ohmic overpotential, a traditional YSZ-like decay, as well as a linear decay can in principle 


\section{Cu-Ni/SDC/LSCF-GDC, $20 \% \mathrm{H}_{2} 80 \% \mathrm{~N}_{2}, 700^{\circ} \mathrm{C}$}
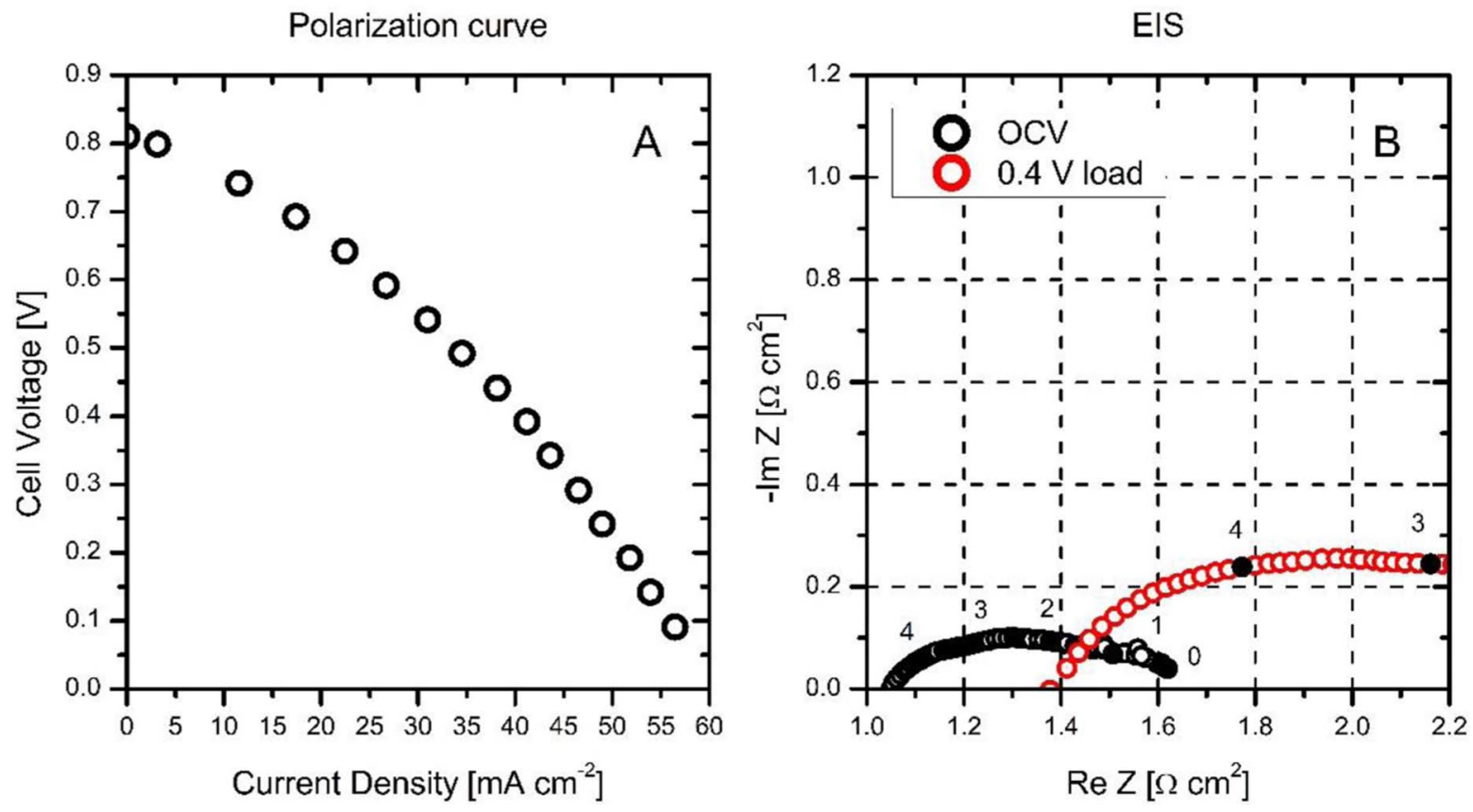

Figure 11. Cu-Ni/SDC/LSCF-GDC cell. Experiments with $20 \% \mathrm{H}_{2}, 80 \% \mathrm{~N}_{2}$ mixtures at $700{ }^{\circ} \mathrm{C}$. Constant $3 \% \mathrm{H}_{2} \mathrm{O}$ humidification. Panels: A) Polarization curve; B) EIS spectra at OCV (o) and $0.4 \mathrm{~V}$ voltage loading (o). Operating conditions for the EIS tests: $10 \mathrm{kHz}-0.1 \mathrm{~Hz}$ frequency range, $10 \mathrm{mV}$ amplitude. The logarithm of the frequency decade is reported.

be achieved in proximity of the OCV, which also suggests why several different profiles are found in the experimental literature on SDC- and GDC-based cells. ${ }^{12,35}$

A comparison between the overpotentials of the experiments at $100 \% \mathrm{H}_{2}$ and $30 \% \mathrm{H}_{2}$ (Figure 12B) helps in rationalizing the decrease of the $\mathrm{OCV}$ as a function of the inlet $\mathrm{H}_{2}$ concentration. Passing from $100 \%$ to $30 \% \mathrm{H}_{2}$, the cathodic overpotential experiences no appreciable variation, while the Nernst potential decreases, as expected. The anodic activation overpotential keeps almost unaltered at OCV. Notably, the ohmic loss in the $30 \% \mathrm{H}_{2}$ case maintains always lower

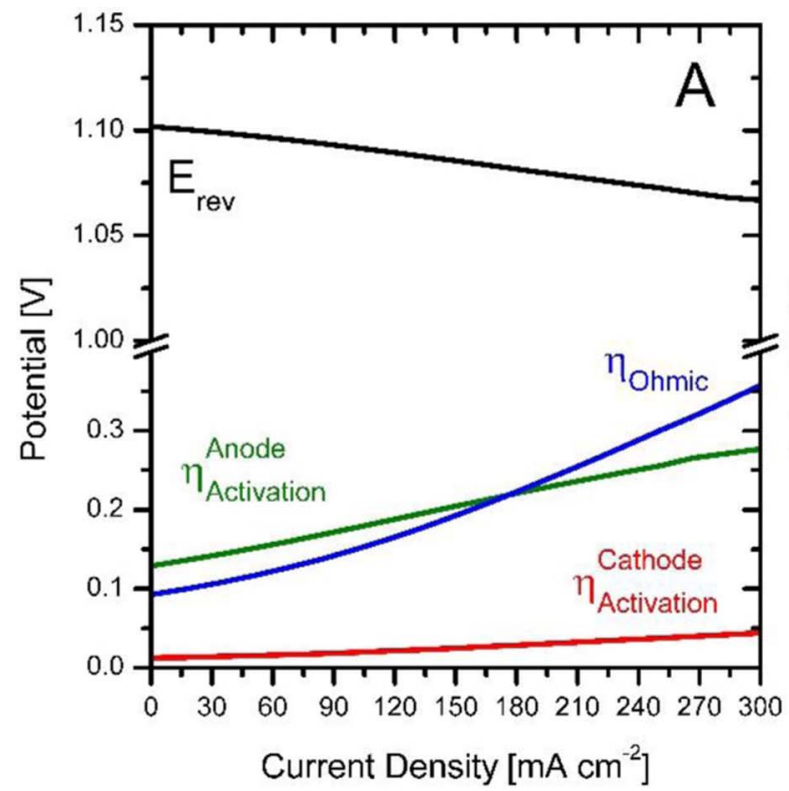

than the $100 \% \mathrm{H}_{2}$ case $(50 \mathrm{mV}$ vs. $90 \mathrm{mV}$ at $\mathrm{OCV})$, due to the fact that the electronic leakage current is smaller (Figure 9A) and so is the ionic current in the electrolyte. Nonetheless, the decrease of the nernstian term prevails and the OCV is seen to decrease when the inlet mixture goes from concentrated to diluted $\mathrm{H}_{2}$. Hence, in the present case, the effect is still driven by thermodynamics. This however could not be the case for MIEC-based cells with different morphology, structure and electrode composition. Depending on the specific balance between the electrode overpotentials and the ohmic loss, almost constant OCV can be also observed when the $\mathrm{H}_{2}$ concentration is varied.

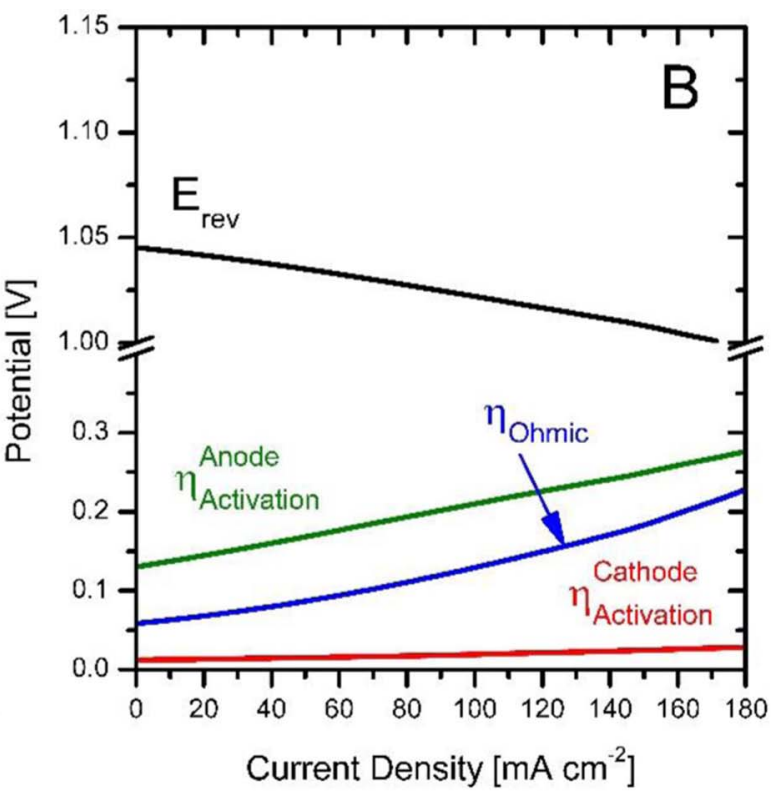

Figure 12. Overpotentials and reversible Nernst potential as a function of current density for the test at $100 \% \mathrm{H}_{2}$ (panel A) and for the test at $30 \% \mathrm{H}_{2}$ (panel B) at $700^{\circ} \mathrm{C}$. 


\section{Conclusions}

In the present work, a distributed charge-transfer model of an IT-SOFC with a MIEC electrolyte is developed and validated. The model includes a physically-based description of the electronic leakage current in the electrolyte, together with conservation equations for mass and charge. The model is applied to simulate polarization curves and impedance spectra collected on a cell based on a Samaria doped Ceria electrolyte, with an infiltrated $\mathrm{Cu}-\mathrm{Pd}-\mathrm{CZ} 80 / \mathrm{SDC}$ anode and a composite LSCF-GDC cathode. $\mathrm{H}_{2}$ electro-oxidation experiments are examined, at $700^{\circ} \mathrm{C}$ with $\mathrm{H}_{2} / \mathrm{N}_{2}$ mixtures and varying the amount of $\mathrm{H}_{2}$. Global power law rates are taken into account for the electrochemical semi-reactions. For each electrode, the exchange current density and the capacitance values are evaluated by fitting the experimental curves. The polarization and impedance spectra are fairly well simulated: a close description is obtained in the case of the polarization, with reliable prediction of the OCV and of the current density; a reasonable description is obtained for the impedance spectra, with good prediction of the real component in terms of ohmic resistance and polarization resistance. The calculated profiles of the electronic and ionic currents along the cell thickness under OCV and load confirm the existence of conditions wherein the leakage current prevails, strongly hindering the overall current extraction and leading to a local inversion of the electrical current flow. The experimental investigation based on the impedance spectra reveals that the measured ohmic resistance increases when the $\mathrm{H}_{2}$ molar fraction decreases, and when the voltage load increases. The model analysis allows to rationalize this effect, which is associated to the dependence of the electrical conductivity of the electrolyte on the local $\mathrm{H}_{2}$ partial pressure as well as, macroscopically, to the leakage current within the MIEC electrolyte. The model presented can be also used as a tool for estimating the EAT extension of the electrodes, and for the optimization of the IT-SOFC design in terms of materials and dimensions of the layers.

\section{Acknowledgments}

Funding from MIUR-Italy (PRIN project 2010KHLKFC) is gratefully acknowledged.

\section{List of Symbols}

$a_{v}$

B

$\mathrm{C}_{\mathrm{DL}} \quad$ double layer capacity $\left[\mathrm{F} \mathrm{m}^{-2}\right]$

$\mathrm{C}_{\mathrm{i}} \quad$ concentration of the ith species [ $\left[\mathrm{mol} \mathrm{m}^{-3}\right.$ ]

$\mathrm{C}_{\text {tot }} \quad$ total concentration of the gas phase $\left[\mathrm{mol} \mathrm{m}^{-3}\right]$

$\mathrm{d}_{\mathrm{p}} \quad$ particle diameter $[\mathrm{m}]$

$D_{i, j}^{M o l}$

$D_{i}^{K n u}$

$\mathrm{E}_{\mathrm{act}}$

$\mathrm{E}_{0}$

$\mathrm{E}_{\text {rev }}$

$\mathrm{F}$

$\mathrm{F}_{\mathrm{i}}{ }^{\text {in }}$

$\mathrm{F}_{\mathrm{i}}$ out

i

$\mathrm{i}_{0}$

$\mathrm{J}_{\mathrm{i}}$

$\mathrm{k}^{\text {eq }}$

L

MM

$\mathrm{n}_{\mathrm{e}-}$

$\mathrm{P}$

$\mathrm{P}_{\mathrm{i}}$

R molecular binary diffusion of the ith species in the $j$ th species $\left[\mathrm{cm}^{2} \mathrm{~s}^{-1}\right]$ Knudsen diffusion of the ith species $\left[\mathrm{cm}^{2} \mathrm{~s}^{-1}\right]$ activation energy $\left[\mathrm{J} \mathrm{mol}^{-1}\right]$ reference potential [V] Nernstian potential [V] Faraday constant $\left[\mathrm{C} \mathrm{mol}^{-1}\right]$ inlet molar flow rate of the ith species $\left[\mathrm{mol} \mathrm{s}^{-1}\right]$ outlet molar flow rate of the ith species $\left[\mathrm{mol} \mathrm{s}^{-1}\right.$ ] current density $\left[\mathrm{A} \mathrm{m}^{-2}\right]$ exchange current density [A $\left.\mathrm{A}^{-2}\right]$ molar flow of the ith species [ $\mathrm{mol} \mathrm{m}^{-2} \mathrm{~s}^{-1}$ ] thermodynamic equilibrium constant layer thickness [m] molar mass $\left[\mathrm{g} \mathrm{mol}^{-1}\right.$ ] number of electrons exchanged in the electro-oxidation reaction pressure $[\mathrm{Pa}]$ partial pressure of the ith species [Pa] gas constant $\left[\mathrm{J} \mathrm{mol}^{-1} \mathrm{~K}^{-1}\right]$

$R_{\text {pol }}$
$R_{\infty}$
$r_{j}$
$r_{P}$
$T$
$t$
$V_{\text {cell }}$
$V_{\text {CSTR }}$
$x_{i}$
$Z$
$z$

polarization resistance $\left[\Omega \mathrm{cm}^{2}\right]$ ohmic resistance $\left[\Omega \mathrm{cm}^{2}\right]$ rate of the $\mathrm{jth}$ reaction $\left[\mathrm{mol} \mathrm{m} \mathrm{m}^{-2} \mathrm{~s}^{-1}\right.$ ] pore radius $[\mathrm{cm}]$ temperature $[\mathrm{K}]$ time [s] cell voltage [V] CSTR volume $\left[\mathrm{m}^{3}\right]$ molar fraction of the ith species impedance $\left[\Omega \mathrm{cm}^{2}\right]$ axial coordinate $[\mathrm{m}]$

\section{Greek}

$\alpha$

$\varepsilon$ $\eta_{\text {act }}$ $\mu$

$v$ $\sigma$ $\tau$ $\varphi$ $\psi$ $\omega$

an

calc

cat

cell

eff

el

ely electro $\exp$

i

j

ion symmetry factor electrode porosity activation overpotential [V] dynamic viscosity of the gas mixture [Pa s] stoichiometric coefficient conductivity $[\mathrm{S} / \mathrm{m}]$ tortuosity potential [V] volume fraction of the conductive phase frequency $[\mathrm{Hz}]$

\section{Subscripts and Superscripts}

anode calculated cathode referred to the cell effective electronic electrolyte referred to the electrochemical reaction experimental ith species jth species ionic

\section{References}

1. B. C. H. Steele, Solid State Ionics, 129(1), 95 (2000).

2. D. J. L. Brett, A. Atkinson, N. P. Brandon, and S. J. Skinner, Chemical Society Reviews, 37(8), 1568 (2008).

3. B. Dalslet, P. Blennow, P. V. Hendriksen, N. Bonanos, D. Lybye, and M. Mogensen, Journal of Solid State Electrochemistry, 10(8), 547 (2006).

4. H. Inaba and H. Tagawa, Solid State Ionics, 83(1), 1 (1996).

5. E. C. C. Souza, W. C. Chueh, W. Jung, E. N. S. Muccillo, and S. M. Haile, Journal of The Electrochemical Society, 159(5), K127 (2012).

6. I. Riess, Journal of The Electrochemical Society, 128(10), 2077 (1981).

7. J. Jamnik and J. Maier, Journal of The Electrochemical Society, 146(11), 4183 (1999).

8. W. C. Chueh, W. Lai, and S. M. Haile, Solid State Ionics, 179(21), 1036 (2008).

9. W. Lai and S. M. Haile, Journal of the American Ceramic Society, 88(11), 2979 (2005).

10. A. Atkinson, S. A. Baron, and N. P. Brandon, Journal of The Electrochemical Society, 151(5), E186 (2004)

11. K. L. Duncan and E. D. Wachsman, Journal of The Electrochemical Society, 156(9), B1030 (2009).

12. K. L. Duncan, K. -T. Lee, and E. D. Wachsman, Journal of Power Sources, 196(5), 2445 (2011).

13. S. Shen, Y. Yang, L. Guo, and H. Liu, Journal of Power Sources, 256, 43 (2014)

14. H. Zhu, A. Kromp, A. Leonide, E. Ivers-Tiffée, O. Deutschmann, and R. J. Kee, Journal of The Electrochemical Society, 159(7), F255 (2012).

15. H. Zhu, R. J. Kee, V. M. Janardhanan, O. Deutschmann, and D. G. Goodwin, Journal of The Electrochemical Society, 152(12), A2427 (2005).

16. P. Costamagna, P. Costa, and V. Antonucci, Electrochimica Acta, 43(3), 375 (1998).

17. V. M. Janardhanan and O. Deutschmann, Electrochimica Acta, 56(27), 9775 (2011).

18. H. Zhu and R. J. Kee, Journal of The Electrochemical Society, 153(9), A1765 (2006).

19. Y. Shi, N. Cai, C. Li, C. Bao, E. Croiset, J. Qian, Q. Hu, and S. Wang, Journal of The Electrochemical Society, 155(3), B270 (2008). 
20. A. Bertei, G. Arcolini, J. P. Ouweltjes, Z. Wuillemin, P. Piccardo, and C. Nicolella, Electrochimica Acta, 208, 129 (2016).

21. T. Yang, H. Sezer, I. B. Celik, H. O. Finklea, and K. Gerdes, ECS Transactions, 68(1), 2397 (2015).

22. A. Bertei, J. Mertens, and C. Nicolella, Electrochimica Acta, 146, 151 (2014).

23. A. Donazzi, M. Rahmanipour, M. Maestri, G. Groppi, L. Bardini, A. Pappacena, and M. Boaro, Journal of Power Sources, 306, 467 (2016).

24. R. J. Gorte, S. Park, J. M. Vohs, and C. H. Wang, Advanced Materials, 12(19), 1465 (2000).

25. D. Chen, Z. Lin, H. Zhu, and R. J. Kee, Journal of Power Sources, 191(2), 240 (2009).

26. M. Gödickemeier and L. J. Gauckler, Journal of The Electrochemical Society, 145(2), 414 (1998)

27. X. Zhang, M. Robertson, C. Deĉes-Petit, W. Qu, O. Kesler, R. Maric, and D. Ghosh, Journal of Power Sources, 164(2), 668 (2007).

28. D. Cui, Q. Liu, and F. Chen, Journal of Power Sources, 195(13), 4160 (2010).

29. J. W. Stevenson, T. R. Armstrong, R. D. Carneim, L. R. Pederson, and W. J. Weber, Journal of The Electrochemical Society, 143(9), 2722 (1996).

30. H. J. M. Bouwmeester, M. W. Den Otter, and B. A. Boukamp, Journal of Solid State Electrochemistry, 8(9), 599 (2004).

31. K. Huang and J. B. Goodenough, in Solid Oxide Fuel Cell Technology: Principles, Performance and Operations, p. 1, Woodhead Publ Ltd, Cambridge, (2009).

32. R. Krishna and J. A. Wesselingh, Chemical Engineering Science, 52(6), 861 (1997).

33. W. G. Bessler, S. Gewies, and M. Vogler, Electrochimica Acta, 53(4), 1782 (2007).

34. W. G. Bessler, Solid State Ionics, 176(11), 997 (2005).

35. C. Lu, W. L. Worrell, R. J. Gorte, and J. M. Vohs, Journal of The Electrochemical Society, 150(3), A354 (2003).
36. C. Lu, S. An, W. L. Worrell, J. M. Vohs, and R. J. Gorte, Solid State Ionics, 175(1), 47 (2004).

37. T. Matsui, T. Kosaka, M. Inaba, A. Mineshige, and Z. Ogumi, Solid State Ionics, 176(7), $663(2005)$

38. X. Fang, G. Zhu, C. Xia, X. Liu, and G. Meng, Solid State Ionics, 168(1), 31 (2004).

39. J. Liu, B. D. Madsen, Z. Ji, and S. A. Barnett, Electrochemical and Solid-State Letters, 5(6), A122 (2002).

40. Y. D. Zhen, A. I. Y. Tok, S. P. Jiang, and F. Y. C. Boey, Journal of Power Sources, 178(1), 69 (2008).

41. Y. Chen, Y. Zhang, G. Xiao, Z. Yang, M. Han, and F. Chen, ChemElectroChem, 2(5), 672 (2015).

42. S. Choi, J. Shin, K. M. Ok, and G. Kim, Electrochimica Acta, 81, 217 (2012).

43. Y. Shi, N. Cai, and C. Li, Journal of Power Sources, 164(2), 639 (2007).

44. E. Dogdibegovic, W. Guan, J. Yan, M. Cheng, and X. -D. Zhou, Journal of The Electrochemical Society, 163(13), F1344 (2016).

45. Z. Wuillemin, Y. Antonetti, C. Beetschen, O. Millioud, S. Ceschini, H. Madi, and J. Van herle, ECS Transactions, 57(1), 561 (2013).

46. B. Kenney and K. Karan, Journal of The Electrochemical Society, 157(8), B1126 (2010).

47. V. Yurkiv, R. Costa, Z. Ilhan, A. Ansar, and W. G. Bessler, Journal of The Electrochemical Society, 161(4), F480 (2014).

48. F. S. Baumann, J. Fleig, H. -U. Habermeier, and J. Maier, Solid State Ionics, 177(11), 1071 (2006)

49. C. Nicolella, A. Bertei, M. Viviani, and A. Barbucci, Journal of Applied Electrochemistry, 39(4), 503 (2009).

50. S. Gewies, W. G. Bessler, V. Sonn, and E. Ivers-Tiffee, ECS Transactions, 7(1), 1573 (2007). 